\title{
Assessment of Precipitating Marine Stratocumulus Clouds in the E3SMv1 Atmosphere Model: A Case Study from the ARM MAGIC Field Campaign ${ }^{0}$
}

\author{
X. Zheng, ${ }^{\text {a }}$ S. A. Klein, ${ }^{\text {a }}$ V. P. Ghate, ${ }^{\text {b }}$ S. SAntos, ${ }^{\text {c }}$ J. McGibbon,${ }^{\text {d }}$ P. CAldwell, ${ }^{\text {a }}$ \\ P. BOGENSCHUTZ, ${ }^{\mathrm{a}}$ W. Lin, ${ }^{\mathrm{e}}$ AND M. P. CADEDDU ${ }^{\mathrm{b}}$ \\ ${ }^{a}$ Cloud Processes Research and Modeling Group, Lawrence Livermore National Laboratory, Livermore, California \\ ${ }^{\mathrm{b}}$ Environmental Science Division, Argonne National Laboratory, Lemont, Illinois \\ ${ }^{\mathrm{c}}$ Department of Applied Mathematics, University of Washington, Seattle, Washington \\ ${ }^{\mathrm{d}}$ Department of Atmospheric Sciences, University of Washington, Seattle, Washington \\ ${ }^{\mathrm{e}}$ Brookhaven National Laboratory, Upton, New York
}

(Manuscript received 18 October 2019, in final form 4 May 2020)

\begin{abstract}
This paper presents a process-oriented evaluation of precipitating stratocumulus and its transition to cumulus in version 1 of the Energy Exascale Earth System Model (E3SMv1) using comprehensive case-study observations from a field campaign of the Atmospheric Radiation Measurement program (ARM). The E3SMv1 single-column model (SCM) of the marine boundary layer and its low clouds and precipitation are compared to observations including subcloud drizzle retrievals from a combination of Doppler radar and lidar backscatter measurements. The SCM is also compared to a large-eddy simulation (LES) of the same case. The combination of advanced remote sensing observations and LES is a powerful framework to evaluate the physical parameterizations of large-scale models. Given the observed large-scale environment, the E3SMv1 SCM realistically represents the evolution of clouds and boundary layer structure during the stratocumulusto-cumulus transition. The model well simulates the liquid water path and its diurnal cycle in the stratocumulus period as well as the two-layer vertical thermodynamic structure and lower cloud fraction in the transition period. E3SMv1's success in simulating the cloud in the stratocumulus period permitted examination of its precipitation processes. Here problems were identified with E3SMv1 producing an unrealistically small subcloud precipitation fraction, an unrealistic double peak in the vertical profiles of precipitation mass, and drizzle that evaporates too close to the surface. Further model diagnostics determined that these unrealistic characteristics resulted from an overly long microphysics time step and an unrealistic parameterization of the precipitation fraction. These results imply that careful consideration of these issues is needed in order to better simulate precipitation processes in marine stratocumulus.
\end{abstract}

\section{Introduction}

Because of the significant radiative impact of stratocumulus (Sc) on Earth's energy budget (Hartmann et al. 1992; Wood 2012; Quaas et al. 2009) and the persistent model biases over the Sc regions, general circulation models (GCMs) have spent tremendous development efforts on improving the representation of Sc and the Sc-related physical processes (Flato et al. 2013; Lin et al. 2014). The first version of the U.S. Department of

Supplemental information related to this paper is available at the Journals Online website: https://doi.org/10.1175/MWR-D-190349.s1.

Corresponding author: Xue Zheng, zheng7@llnl.gov
Energy (DOE)'s new Energy Exascale Earth System Model (E3SMv1) increases the atmospheric vertical resolution below $3 \mathrm{~km}$ to 22 layers compared to 10 layers in its predecessor, the Community Atmosphere Model (CAM) version 5.3 (E3SMv0; Xie et al. 2018). The substantially increased vertical resolution in the lower troposphere better resolves the fine structure of the Sc layer and planetary boundary layer (PBL) processes (Wood 2012). Besides the change in vertical resolution, E3SMv1 unifies the treatment of PBL turbulence, shallow convection, and cloud macrophysics for both stratiform and shallow convective clouds through the inclusion of a higher-order closure (HOC) scheme called Cloud Layers Unified by Binormals (CLUBB) (Golaz et al. 2002a; Larson and Golaz 2005). Furthermore, cloud and precipitation microphysics for stratiform and 
shallow convective clouds are calculated by a new twomoment microphysics scheme (MG2; Gettelman and Morrison 2015), in which a prognostic precipitation formulation replaces the former diagnostic precipitation formulation in the CAM5 microphysics scheme (MG1; Morrison and Gettelman 2008).

CLUBB calculates cloud properties through a probability distribution function (PDF) approach for both Sc and cumulus $(\mathrm{Cu})$ clouds. The prognostic second-order turbulent fluxes in CLUBB combined with prognostic precipitation and other advanced microphysics in MG2 should permit a realistic representation of cloud-drizzleturbulence interactions. Previous studies found that CLUBB and MG2 can simulate a smoother Sc-to-Cu transition over the subtropical eastern oceans, more realistic cloud microphysical processes, and weaker aerosol-cloud interactions in comparison with CAM5.3 default schemes (Bogenschutz et al. 2013; Gettelman et al. 2015; Kubar et al. 2015; Zheng et al. 2016; Song et al. 2018). On the other hand, E3SMv1 atmospheric simulations with prescribed SST and coupled simulations still suffer the underestimation of Sc cloudiness off the west coasts of subtropical continents and an overly strong aerosol effective radiative forcing that is dominated by aerosol-cloud interactions (Xie et al. 2018; Golaz et al. 2019; Rasch et al. 2019). Since CLUBB and MG2 treat processes that evolve more rapidly than the typical model time step of $1800 \mathrm{~s}$, their effects are included by breaking the model time step into several substeps and integrating CLUBB and MG2 together over each of these substeps. Consequently, CLUBB and MG2 schemes couple with each other much more frequently and more tightly than the parameterizations in earlier model versions. The short coupling interval between CLUBB and MG2 is not, however, sufficient to prevent unrealistic model behavior if any of the physical processes in these two schemes are poorly treated. In particular, the CLUBB-MG2 coupling is found to be sensitive to precipitation processes (Zheng et al. 2017). These interactions need to be fully examined with observational references.

Recent ground-based observations have shown that precipitation commonly occurs in the marine Sc regime and precipitation is a significant component for the PBL moisture budget (Rémillard et al. 2012; Wood et al. 2016). By combining Doppler radar and backscatter lidar observations to more accurately estimate the size distribution and flux of precipitation below cloud, ARM provides a drizzle retrieval that serves as a comprehensive observational reference to evaluate the precipitation processes for marine Sc in GCMs (O'Connor et al. 2005). ARM drizzle and turbulence retrievals from the ARM Eastern North Atlantic site have been analyzed to investigate the impact of drizzle evaporation on turbulence in the Sc-topped PBL (Ghate and Cadeddu 2019). These ARM observations have also been used to evaluate lowcloud precipitation processes in the European Centre for Medium-Range Weather Forecasts model (Ahlgrimm and Forbes 2014). Here, we use ARM drizzle observations to evaluate the performance of the E3SMv1 atmosphere model on simulating precipitating marine Sc.

From October 2012 to September 2013, the Marine ARM Global Energy and Water Cycle Experiment Cloud System Study/Working Group on Numerical Experimentation (GCSS/WGNE) Pacific Cross-Section Intercomparison (GPCI) Investigation of Clouds (MAGIC) campaign used a regular commercial ship to collect intensive observations of marine low clouds, precipitation, and PBL structure along the transect between Los Angeles, California, and Honolulu, Hawaii (Lewis and Teixeira 2015; Zhou et al. 2015). This transect nicely covers the climatological transition between marine $\mathrm{Sc}$ and $\mathrm{Cu}$ clouds, which is particularly difficult to capture in GCMs (Wyant et al. 2010; Teixeira et al. 2011). To better identify the contribution of the model parameterizations and minimize the contribution of the nonlocal influences, we use single-column model (SCM) simulations with constrained large-scale forcing from MAGIC observations and analysis data. Furthermore, large-eddy simulations (LES) with the same large-scale forcing add supplemental information to the model process-level evolution (McGibbon and Bretherton 2017). Therefore, the scientific objective of this study is to evaluate E3SMv1's performance in simulating precipitating marine low clouds and precipitation through use of ARM MAGIC observations and LES.

Section 2 describes the data and methodology, including the MAGIC field campaign observations and LES, and the physics and SCM setup of the E3SMv1 atmosphere model. Section 3 presents the evaluation of the default SCM simulation and the model deficiencies in precipitation processes. Section 4 discusses the results from other SCM simulations using shorter microphysics time steps and modified physical parameterizations. The main conclusions are summarized in section 5 .

\section{Data and methods}

\section{a. MAGIC field campaign}

To advance the understanding of the MBL decoupling and the Sc-to- $\mathrm{Cu}$ transition over eastern subtropical ocean basins and to obtain observational benchmarks for improving the representation these cloud regimes in GCMs, ARM conducted the MAGIC field campaign between October 2012 and September 2013 (Lewis and Teixeira 2015). The ship-based MAGIC field campaign was deployed on the Horizon Lines cargo container 


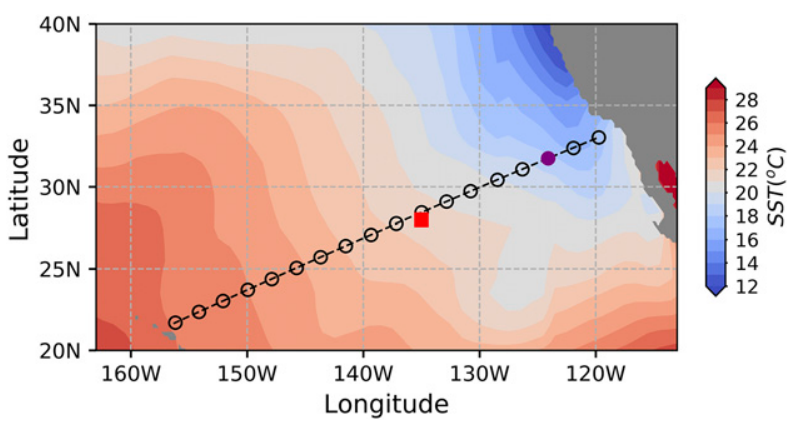

FIG. 1. The NOAA weekly SST during 21-27 Jul $2013\left({ }^{\circ} \mathrm{C}\right.$, color filled) and the ship track (black dashed line) for MAGIC Leg 15A (20-25 Jul 2013). The red square shows the latitude and longitude of SCM simulations in this study. The black open circles indicate the sounding locations. The purple circle denotes the location of the sounding used as the initial condition.

Spirit, which conducted 20 round trips between Los Angeles, California, and Honolulu, Hawaii (Zhou et al. 2015). This study focuses on the observations during the first half of the 15th round trip named as Leg 15A. Leg 15A was from Los Angeles to Honolulu during 20-25 July 2012 (Fig. 1). A distinct Sc-to-Cu transition was observed during Leg 15A: an unbroken Sc layer with precipitation falling below the cloud occurred during the first couple of days, with a later transition to scattered $\mathrm{Cu}$ clouds (center column of Fig. 2).

\section{1) ARM MEASUREMENTS}

Most of the instruments worked properly during Leg 15A (Zhou et al. 2015). This study analyzes the observed thermodynamic state, cloud and subcloud drizzle properties, surface heat and radiative fluxes and surface precipitation rate. All observational variables in this study are hourly averaged, except radiosonde soundings.

Thermodynamic profiles are available from radiosondes launched four times per day: around 0530, 1130, 1730, and 2330 UTC (Fig. 1). The original vertical resolution of the soundings is $5 \mathrm{~m}$. We average the soundings to a vertical resolution of $50 \mathrm{~m}$ before we estimate the PBL height $\left(Z_{i}\right)$ defined as the height of the maximum vertical gradient of potential temperature between 500 and $2800 \mathrm{~m}$. The thermodynamic profiles from SAM LES and E3SM SCM simulations are also interpolated to the same vertical levels when estimating PBL height.

The difference between stratocumulus cloud base and surface lifted condensation level (LCL) has found to be a good measurement of stratocumulus cloud-topped boundary layer decoupling (Jones et al. 2011). McGibbon and Bretherton (2017, their Fig. 2) found that the LCL of air at a height equal to $70 \%$ of the PBL height $Z_{\mathrm{LCL}}^{0.7 Z_{i}}$ can be a good proxy for stratocumulus cloud base. Generally speaking, $Z_{\mathrm{LCL}}^{150 \mathrm{~m}}$ should be close to $Z_{\mathrm{LCL}}^{0.7 Z_{i}}$ in a well-mixed
PBL and it will separate away from $Z_{\mathrm{LCL}}^{0.7 Z_{i}}$ when the PBL keeps decoupling.

We calculate hourly cloud fraction based on the radar reflectivity from a Ka-band ARM zenith radar (KAZR; $35 \mathrm{GHz}$ ) and hourly low-level cloud cover from a ceilometer with the similar approach used in Zheng et al. (2016). We also estimated hourly cloud fraction from a W-band radar reflectivity (MWACR; $95 \mathrm{GHz}$ ); results are fairly similar between the two instruments except a large portion of scattered Cu clouds on 24 July 2013 are missed by KAZR (not shown). Subcloud drizzle properties including rainwater content and precipitation flux are retrieved by combining KAZR radar and ceilometer lidar observations (O'Connor et al. 2005; Ghate and Cadeddu 2019). Drizzle rate retrievals start from $50 \mathrm{~m}$ below the ceilometer detected cloud base and end at $200 \mathrm{~m}$ above the surface. The uncertainty of the retrieved precipitation flux is $\sim 20 \%$, while the uncertainty of the rainwater content is $\sim 10 \%$. As discussed by Ghate and Cadeddu (2019), subcloud rain retrievals are only available if raindrops are larger than 90 microns in diameter, and the ceilometer backscatter from drizzle is significantly higher than the background aerosol backscatter. With strong aerosol signals, the algorithm will not produce rain retrievals even though the radar echoes detect the hydrometeors below the cloud base. However, this was not a problem during Leg 15A. Furthermore, hourly subcloud drizzle retrievals for Sc clouds can easily be compared with to E3SM SCM and SAM LES model outputs because of the uniform cloud base. This is not the case for the ARM subcloud drizzle retrievals for $\mathrm{Cu}$ clouds which are less reliable because a large part of subcloud precipitation information is missing for clouds that have multiple cloud bases. The hourly fractional occurrence of rain beneath cloud base is calculated based on the KAZR reflectivity below the ceilometer detected cloud base. This fractional rain occurrence fraction profile is extended through the cloud layer by assuming that the entire cloud layer contains precipitation whenever there is drizzle below the ceilometer cloud base. This is consistent with E3SM's assumption, but it might overestimate the fractional occurrence of rain near the cloud top based on the LES results shown in section $3 b$.

The observed cloud liquid water path (LWP) is derived from a three-channel microwave radiometer (MWR) (Cadeddu et al. 2013) and post processed with an LWP optimal estimation scheme to remove the scattering effect from precipitating hydrometeors (Cadeddu et al. 2017). The uncertainty in the retrieved LWP with the postprocessing generally varies between 7 and $15 \mathrm{~g} \mathrm{~m}^{-2}$, while the uncertainty in the retrieved LWP without the postprocessing is about $20 \mathrm{~g} \mathrm{~m}^{-2}$ (Ghate and Cadeddu 2019). 
E3SM SCM CTL

(a) $\mathrm{q}\left(\mathrm{g} \mathrm{kg}^{-1}\right)$

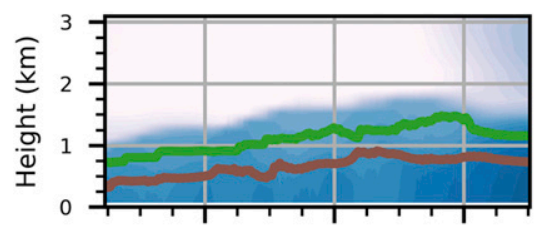

(d) $\theta(\mathrm{K})$

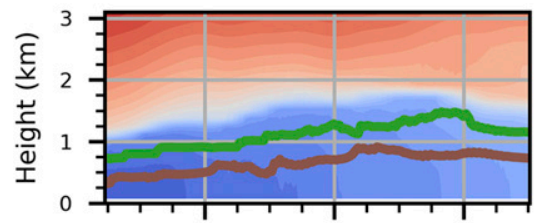

(g) Cloud Fraction

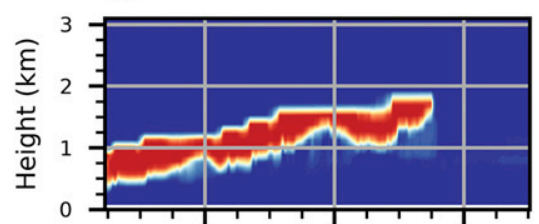

(j) Precip Flux $\left(m m\right.$ day $\left.^{-1}\right)$

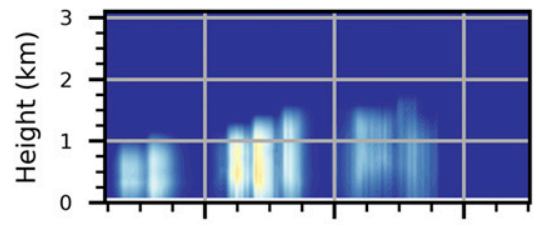

(m) Frac. Occurrence of Rain

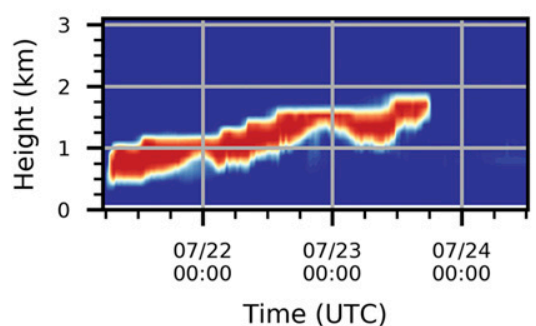

ARM OBS

(b) $\quad \mathrm{q}\left(g \mathrm{~kg}^{-1}\right)$

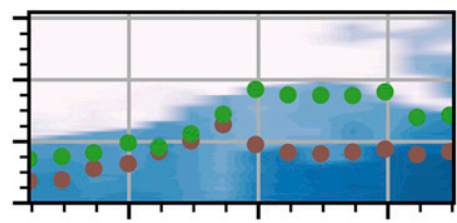

(e) $\theta(\mathrm{K})$

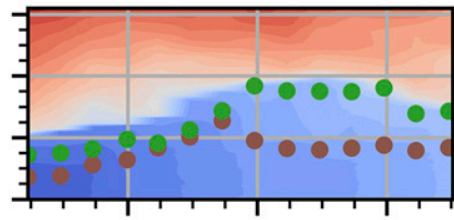

(h) Cloud Fraction

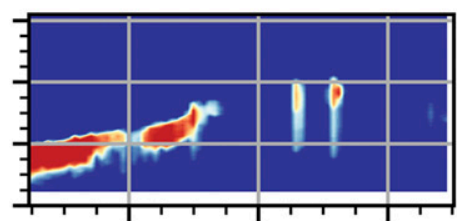

(k) Precip Flux $\left(m m d^{2} y^{-1}\right)$

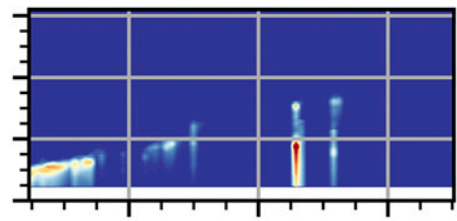

(n) Frac. Occurrence of Rain

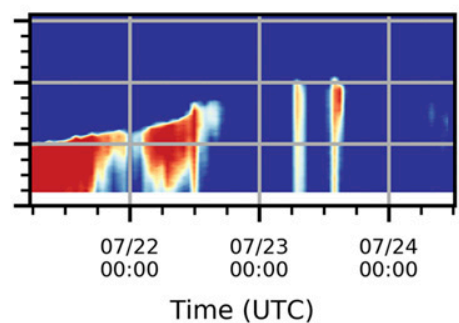

SAM LES

(c) $\quad \mathrm{q}\left(\mathrm{g} \mathrm{kg}^{-1}\right)$

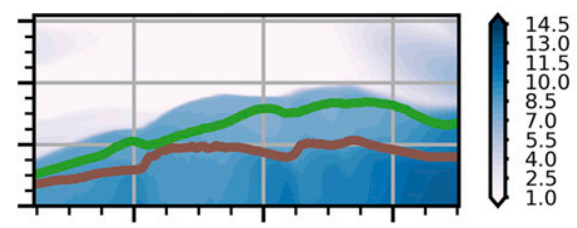

(f) $\theta(\mathrm{K})$

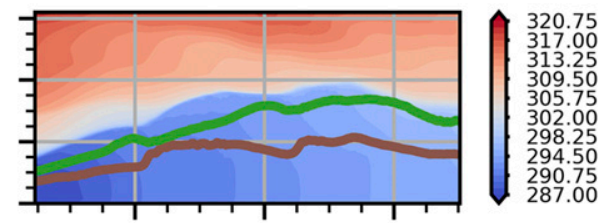

(i) Cloud Fraction

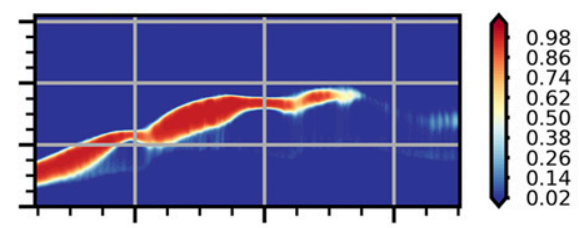

(I) Precip Flux $\left(m m d^{2}{ }^{-1}\right)$

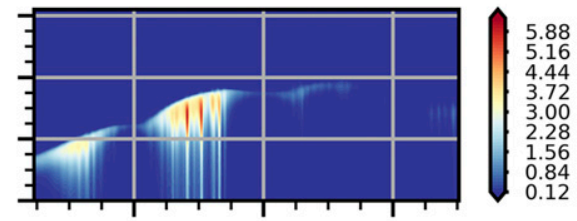

(o) Frac. Occurrence of Rain

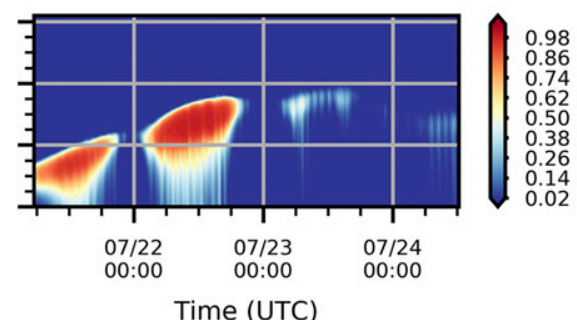

FIG. 2. Time-height evolution of selected variables from Leg 15A for (left) E3SM SCM CTL run, (center) ARM observations, and (right) SAM LES. Variables shown include (a)-(c) specific humidity $q$, (d)-(f) potential temperature $\theta$, (g)-(i) cloud fraction, (j)-(l) precipitation flux, and (m)-(o) fractional occurrence of rain. In (a)-(f), the decoupling status of the boundary layer is illustrated by the relative placement of green and brown lines and dots that, respectively, show the lifting condensation level of air $150 \mathrm{~m}$ above the surface and at a height equal to $70 \%$ of the PBL depth. Note that the SCM variable is a grid mean value, the LES is a domain-average value, and the ARM observation is a $1 \mathrm{~h}$ average value from one point. In (k) ARM precipitation flux observations are only available in the layer between $200 \mathrm{~m}$ above the surface and $50 \mathrm{~m}$ below the cloud base.

The observed surface precipitation rate is measured by an onboard optical rain gauge in the meteorological mast system, which is installed at $\sim 27 \mathrm{~m}$ above mean sea level to avoid the perturbation from the ship (Lewis 2016). Surface downwelling shortwave (SW) and longwave (LW) fluxes are measured by a portable radiation package (PRP). Surface sensible and latent heat fluxes are calculated using the bulk Coupled Ocean-Atmosphere
Response Experiment (COARE) algorithm (Fairall et al. 2003).

\section{2) SAM LES}

McGibbon and Bretherton (2017) showed that LES can skillfully simulate the broad range of observed cloud characteristics and boundary layer structure during MAGIC. Particularly, the LES for Leg 15A reproduces 
the observed PBL decoupling, Sc-to-Cu transition, and precipitation. A full description of these simulations can be found in McGibbon and Bretherton (2017). In brief, the LES model is the System for Atmospheric Modeling (SAM), version 6.10.6 (Khairoutdinov and Randall 2003), that uses a double-moment cloud microphysics without ice microphysics (Morrison et al. 2005) for cloud microphysics. Note that the MG2 cloud microphysics scheme used in E3SMv1 is also based on the Morrison et al. (2005) cloud microphysics scheme but with an additional treatment of subgrid cloud variability due to the coarse resolution of GCMs. The horizontal domain of the LES is $6.4 \times 6.4 \mathrm{~km}^{2}$ with a horizontal resolution of $50 \mathrm{~m}$, while the vertical domain extends to $25.1 \mathrm{~km}$ with 460 vertical levels. The simulation uses a variable vertical resolution and it spaces its highest resolution of $5 \mathrm{~m}$ between 0.6 and $2.1 \mathrm{~km}$. The LES is initialized with the first thermodynamic sounding of Leg 15A (1729 UTC 20 July 2013). Based on ECMWF analysis prepared for the MAGIC field campaign (Ahlgrimm 2015), horizontal advective forcing along the ship track are calculated using the horizontal ship-relative vector wind. Instead of using prescribed surface fluxes, the LES calculates surface fluxes using the modeled atmospheric state together with the prescribed 1-min SST derived from the Infrared Sea Surface Temperature Autonomous Radiometer (ISAR) measurements. Humidity below $3 \mathrm{~km}$ is nudged to the radiosonde sounding profiles with a time scale of 2 days. Above $3 \mathrm{~km}$, both temperature and humidity are nudged to the sounding profiles with a time scale of $30 \mathrm{~min}$. A time-varying uniform cloud droplet number concentration is prescribed based on surface cloud condensation nuclei (CCN) observations and Geostationary Operational Environmental Satellites (GOES) cloud droplet number concentrations. This study mainly analyzes the 20-min domain-averaged model outputs of the PBL, cloud, and precipitation processes.

\section{b. E3SMv1 and SCM simulation setup}

Full descriptions of the model physics in E3SMv1 atmosphere model can be found in Xie et al. (2018) and Rasch et al. (2019). Here we only describe the model information relevant to simulating marine warm clouds. The E3SMv1 atmosphere model has two sets of standard globally uniform horizontal-resolution configurations: $1^{\circ}$ and $0.25^{\circ}$ latitude-longitude. Both configurations include the same 72 vertical levels with 17 levels below $1.5 \mathrm{~km}$; and the model top is at $0.1 \mathrm{hPa}$. As previously mentioned, the combined PBL turbulence, shallow convection, and cloud macrophysics scheme in E3SMv1 is CLUBB. The cloud microphysics scheme for stratiform clouds and shallow convective clouds is
MG2. The deep convection is the Zhang-McFarlane scheme that uses a dilute parcel method with vertical transport of horizontal momentum (Zhang and McFarlane 1995; Neale et al. 2008; Richter and Rasch 2008). The Zhang-McFarlane scheme can be triggered in the shallow convective cloud regime if the convective available potential energy (CAPE) exceeds the threshold of $70 \mathrm{~J} \mathrm{~kg}^{-1}$ (Zheng et al. 2016). The model physics time step for $1^{\circ}$ resolution is $1800 \mathrm{~s}$. CLUBB and MG2 have a sub-time step of 300 s (i.e., CLUBB and MG2 run sequentially 6 times within each physics time step).

We use the SCM mode of E3SMv1 source code version maint-1.0 (https://e3sm.org/model/running-e $3 \mathrm{sm} /$ e3sm-quick-start/). We use the same horizontal advectiveforcings and SST as used in the SAM LES (McGibbon and Bretherton 2017). The vertical advection terms for each time step are calculated from the prescribed largescale vertical velocity and the model-simulated atmospheric state. The initial conditions are from the third radiosonde sounding launched at 0529 UTC 21 July 2013. This time was chosen to avoid the problem that the modeled cloud layer is too low to have the subcloud precipitation comparable with the ARM observation if the simulation is initialized with the first two radiosondes. To exclude the uncertainties from the modeled aerosolcloud interactions and facilitate comparison to the LES, the cloud droplet number concentration is prescribed as a constant number of $60 \mathrm{~cm}^{-3}$ for the SCM simulation. The horizontal wind field is nudged toward the ECMWF analysis wind field with a nudging coefficient of $1 / 3600 \mathrm{~s}^{-1}$. Humidity $q$ and temperature $T$ are nudged toward the ECMWF analysis fields with a height-varying time scale. Above $550 \mathrm{hPa}, q$ and $T$ are nudged toward the ECMWF analysis with a nudging coefficient of $1 / 3600 \mathrm{~s}^{-1}$. Below $750 \mathrm{hPa}$, the nudging coefficient is zero. Between 550 and $750 \mathrm{hPa}$, the nudging coefficient is an interpolated value as a function of the distance from the model level to $550 \mathrm{hPa}$. Additional sensitivity test shows that the results and conclusions are not sensitive to the nudging method. Because the changes in the incoming solar radiation due to the time-varying latitude and longitude along the ship track is no more than $\pm 1 \mathrm{~h}$, the SCM simulations are placed at a fixed location $\left(28^{\circ} \mathrm{N}, 135^{\circ} \mathrm{W}\right)$ near the middle of the ship track (Fig. 1).

We conduct a set of SCM simulations as shown in Table 1 to evaluate the model performance and estimate the impacts of different MG2 time steps and a different precipitation fraction method on the simulated clouds and precipitation. Each simulation lasts $78 \mathrm{~h}$ from 0530 UTC 21 July to 1230 UTC 24 July 2013. The model variables used in this study are 30-min outputs. 
TABLE 1. Summary of the SCM simulations.

\begin{tabular}{cccl}
\hline \hline Expt & $\begin{array}{c}\text { Precipitation fraction } \\
\text { method }\end{array}$ & $\begin{array}{c}\text { MG2 time } \\
\text { step (s) }\end{array}$ & Case name \\
\hline CTL & The in-cloud method & 300 (default) & CTL \\
& (default) & 150 & CTL_150S \\
& & 100 & CTL_100S \\
& & 60 & CTL_60S \\
MGRD & The mass-gradient & 300 (default) & MGRD \\
& method $(\alpha=2$, & 150 & MGRD_150S \\
& $\beta=1)$ & 100 & MGRD_100S \\
& & 60 & MGRD_60S \\
& & 30 & MGRD_30S \\
\hline
\end{tabular}

\section{Results from E3SM SCM CTL}

\section{a. The Sc-to-Cu transition}

During Leg 15A, SST gradually increases by $8 \mathrm{~K}$ (Fig. 1). The observed boundary layer starts as a fairly well-mixed PBL capped by an overcast Sc layer, especially during the nighttime (Figs. 2 and 3). As it keeps growing to $\sim 2 \mathrm{~km}$ on 23 July 2013 , the boundary layer decoupling increases, as indicated by the much greater distance between $Z_{\mathrm{LCL}}^{150 \mathrm{~m}}$ and $Z_{\mathrm{LCL}}^{0.7 Z_{i}}$ (Figs. 2a-f). Meanwhile, the overcast Sc layer starts breaking apart near the end of 23 July 2013 and eventually transitions to $\mathrm{Cu}$ on 23 July 2013 (Figs. 2 and 3c). The decreasing of the observed surface downwelling LW flux and the increasing of SW flux (Figs. 3g,h) are consistent with the observed Sc-to-Cu transition in cloud fraction (Fig. 2h). The E3SM SCM CTL boundary layer is also capped by an overcast Sc layer and it keeps growing with a slower rate than the observation and LES. It breaks up and disappears about $18 \mathrm{~h}$ later than ARM observations, which is similar to SAM LES. E3SM SCM CTL captures the general trend over 3 days of the surface fluxes, low-level RH, surface downwelling LW/SW fluxes, and PBL height (Fig. 3). However, the surface downwelling LW flux is too high and the surface downwelling SW flux is too low around 0000 UTC 23 July relative to ARM observations, due to the delayed Sc-to-Cu transition in E3SM SCM CTL. (a) Surface Precipitation Rate

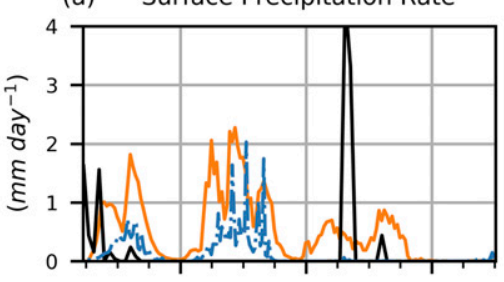

(d) Latent Heat Flux

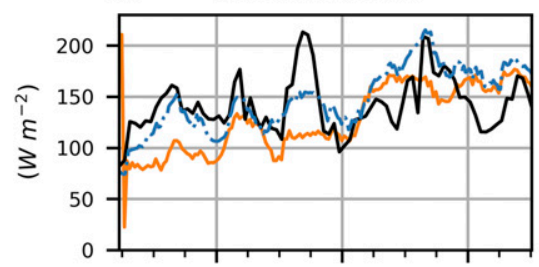

(g) Surface Downwelling LW

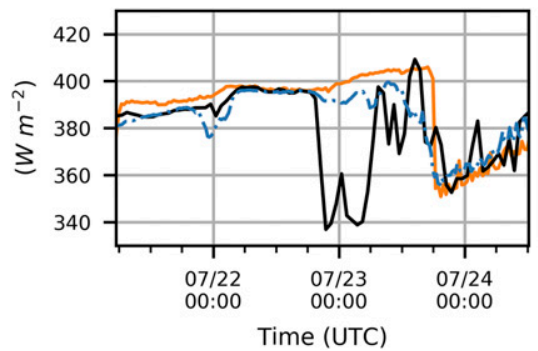

(b)

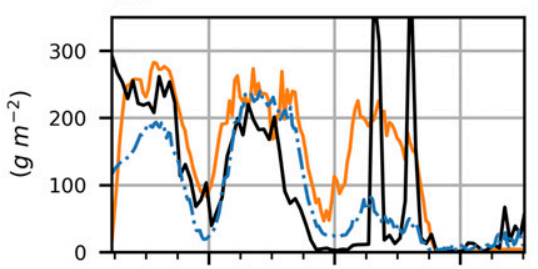

(e) Sensible Heat Flux

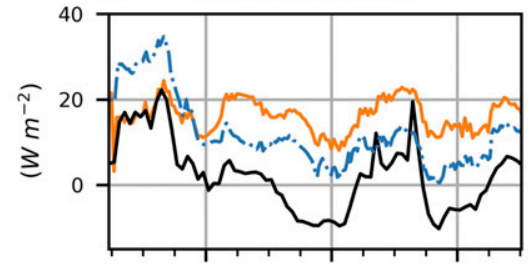

(h) Surface Downwelling SW

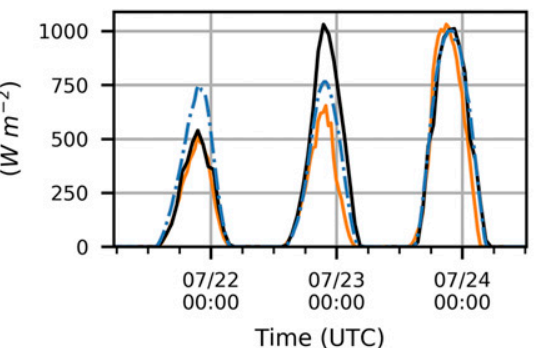

(c)
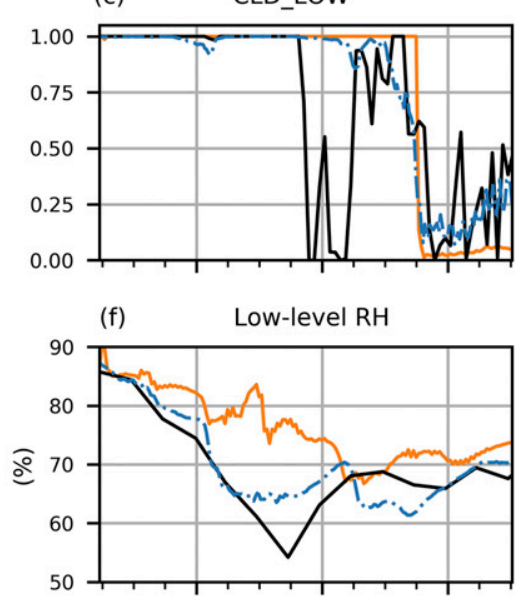

(i)

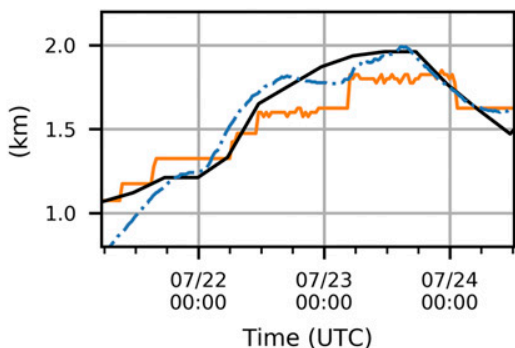

FIG. 3. Time series of (a) surface precipitation rate, (b) LWP, (c) low-level cloud cover, (d) latent heat flux, (e) sensible heat flux, (f) lowlevel relative humidity, (g) surface downwelling LW flux, (h) surface downwelling SW flux, and (i) PBL height. Orange lines, black lines, and blue dashed lines represent SCM CTL simulation, ARM observation, and SAM LES, respectively. The unit of each variable is shown on the $y$ axis. 
Based on the general evaluation, E3SMv1 demonstrates an encouraging model capacity to realistically represent PBL and cloud properties during a Sc-to-Cu transition in the SCM framework. This is encouraging given that the modeling of this transition has challenged the GCM community for many decades (e.g., Karlsson et al. 2010; Teixeira et al. 2011; Xiao et al. 2014). Note that both E3SM SCM CTL and SAM LES simulate a too-late Sc-to-Cu transition (Figs. 2g-i and 3c), excessive precipitation flux, and too much surface precipitation rate on 22 July (Figs. $2 \mathrm{j}-1$ and 3a), although E3SM SCM CTL has larger biases than the LES. The boundary layer is also too moist, and the sensible heat flux is too large on 22 July (Figs. 2a-c and 3e,f) in E3SM SCM CTL and SAM LES as well. These similar biases might partly come from uncertainties in the large-scale forcing since E3SM SCM and SAM LES adopt the same horizontal advection terms and the SST information.

\section{b. The precipitating Sc regime}

Given the importance of the marine Sc regime and the generally successful representation of the Sc phase in E3SM SCM CTL, we will now conduct a more detailed comparison of the Sc-topped BL to both that in the LES and the ARM observations during the first 2 days of Leg 15A to investigate the biases that can be linked to model parameterizations.

The boundary layer starts with a depth of $1 \mathrm{~km}$ on 21 July 2013. Similar to ARM observations and SAM LES, the E3SM SCM CTL PBL and cloud layer grow in height and reach a level of $\sim 1.6 \mathrm{~km}$ after 1200 UTC 22 July 2013 (Figs. 2 and 3). The E3SM SCM CTL PBL is more decoupled than ARM observation during the first 2 days as indicated by the larger distance between $Z_{\mathrm{LCL}}^{150 \mathrm{~m}}$ and $Z_{\mathrm{LCL}}^{0.7 Z_{i}}$. Although the growth of its PBL is weaker than ARM observations and SAM LES (Figs. 2 and 3i), E3SM SCM CTL captures the general evolution of the PBL and Sc layer during the first 2 days. In particular, the E3SM SCM CTL PBL generates an elevated mixed layer above the well-mixed boundary layer in terms of $\theta$ and $q$ (i.e., a double-layer structure) similar to ARM observations and SAM LES near the end of 22 July (Fig. 4). This double-layer PBL indicates that E3SMv1 has the capacity to simulate the process of a new shallow PBL replacing the previous deep PBL. This is likely the result of CLUBB and enhanced model vertical resolution (Bogenschutz et al. 2012; Xie et al. 2018; Neggers et al. 2017).

During this growing stage, the E3SM SCM CTL simulated PBL becomes cooler (Fig. 4 bottom row) than observations, and correspondingly it has a higher surface sensible heat flux (Fig. 3e) after $12 \mathrm{~h}$ of simulation. After another $6 \mathrm{~h}$, the lower PBL becomes too moist in both an absolute and relative sense in comparison to both ARM observations and SAM LES (i.e., between 0000 and 1800 UTC 22 July 2013, Fig. 4, top and middle rows). The PBL also deepens at a slower rate in the SCM relative to that in ARM observations or the SAM LES. Weak PBL growth and cold/moist biases are all symptoms of underpredicted cloud-top entrainment. One possible reason for the underestimated cloud-top entrainment in SCM could be CLUBB only considers the vertical grid scale of cloud-top LW cooling, which is a common practice in GCMs. Cloud-top LW cooling, however, is frequently concentrated in a narrow layer of $50 \mathrm{~m}$ or less and cannot be resolved by the current model resolution. Including the buoyancy flux from the vertically subgrid cloud-top LW cooling in CAM5 with CLUBB is found to improve the modeled stratocumulus clouds through enhance the vertical turbulent mixing and the cloud-top entrainment (Guo et al. 2019). The E3SM SCM CTL PBL inversion structure is also deficient in the sense that the inversion strength is weaker than ARM observations and SAM LES in terms of both $\theta$ and $q$. Our sensitivity test finds that increasing the vertical resolution below $500 \mathrm{hPa}$ by a factor of 3 enhances the PBL inversion strength and the cloud top height (not shown), which is consistent with previous SCM studies with CLUBB (Golaz et al. 2002b). Likely due to the underestimated cloud-top entrainment, the E3SM SCM CTL Sc layer is slightly thicker than ARM observations and the SAM LES (Figs. 2g-i); the cloud LWP, varying between 50 and $280 \mathrm{~g} \mathrm{~m}^{-2}$, is larger than both ARM observations and SAM LES especially during daytime (Fig. 3b). Consistently, the E3SM SCM CTL surface downwelling SW flux is lower than ARM observations and SAM LES on 21 and 22 July (Fig. 3h).

Compared with the PBL thermodynamics and clouds, the E3SM SCM CTL precipitation is more problematic. In observations, 22 July has the weakest precipitation among the first 3 days according to the vertical structure of the precipitation (Figs. $2 \mathrm{k}, \mathrm{n}$ ) and the surface precipitation rate (Fig. 3a). On 22 July, the observed solid Sc layer, with a LWP lower than 21 July by $\sim 50 \mathrm{~g} \mathrm{~m}^{-2}$, has virga with a weaker precipitation flux than 21 and 23 July (Fig. 2k). Virga has been commonly observed by ground-based radars in marine low clouds (Rémillard et al. 2012; Zhou et al. 2015), while GCMs tend to underestimate the occurrence of virga (Ahlgrimm and Forbes 2014; Zheng et al. 2016). On the other hand, both E3SM SCM CTL and SAM LES have surface precipitation on all 3 days. The subcloud precipitation flux in E3SM SCM CTL does not clearly decrease going from cloud base to the surface, in contrast to results from ARM observations and SAM LES (Figs. 2j-1). Furthermore, the fractional occurrence of rain in ARM 

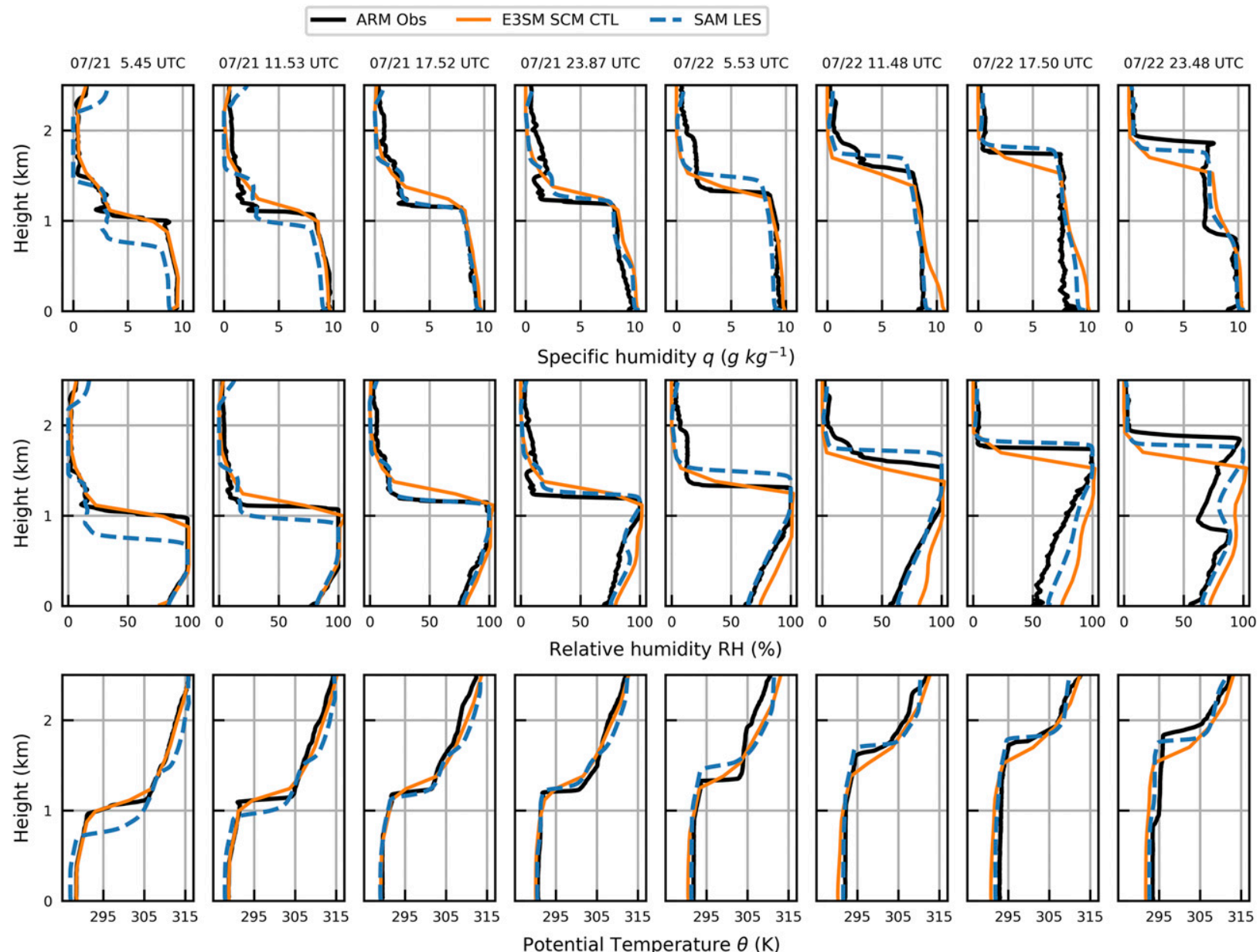

FIG. 4. Vertical profiles of the thermodynamic profiles from ARM radiosondes (black line), E3SM SCM CTL (orange line), and SAM LES (blue dashed line) between 0530 UTC 21 Jul and 2330 UTC 22 Jul 2013: (top) specific humidity, (middle) relative humidity, and (bottom) potential temperature. The time shown at the top of each column is the launching time of the ARM radiosonde. The profiles from E3SM SCM output are the $30 \mathrm{~min}$ model output and the ones from SAM LES are the 20 min model output at the time closest to the radiosonde time.

observations and SAM LES is near 1 at the cloud base and gradually decreases with distance from the cloud base. This behavior is in direct contradiction to the parametric assumptions in the in-cloud precipitation parameterization used by MG2, which assumes belowcloud precipitation fraction is constant in height and equal to whatever the cloud fraction was at the bottom cloud level. In this case, even though SCM subcloud precipitation flux is $>2 \mathrm{~mm}$ day $^{-1}$, SCM subcloud precipitation fraction is $\sim 1 \times 10^{-4}$ which was the minimum allowable cloud fraction during the intermediate steps in MG2, while the precipitation fraction in ARM observations and SAM LES is $>0.1$ for levels with the precipitation flux $>0.5 \mathrm{~mm}$ day $^{-1}$.

A second problem is that the E3SM SCM CTL simulated rainwater mixing ratio $q_{r}$ (Fig. 5a) shows a clear discontinuity at cloud base, while a monotonic decrease below cloud base occurs in ARM observations (Fig. 6a) and SAM LES (Fig. 6b). The mean profiles for 21 July between 1200 and 1800 UTC (Fig. 7) further demonstrate E3SM's unrealistic double peak in the vertical structure of rain rate in comparison with ARM observation and SAM LES. The main precipitation processes that directly change the vertical structure of rainwater below the major cloud layer consist of the evaporation and sedimentation of raindrops. To understand the precipitation biases in E3SM SCM CTL, we need to evaluate these processes. Although there is no direct measurement of the subcloud rain evaporation, in the subcloud layer the vertical gradient of the precipitation flux is a good proxy (cf. Fig. 6e versus Fig. 6c). This reflects the fact that in the budget equation for rainwater mixing ratio, the subcloud tendency from sedimentation, which is equal to -1 times the vertical gradient of 
(a) $q_{r}\left(g g^{-1}\right)$

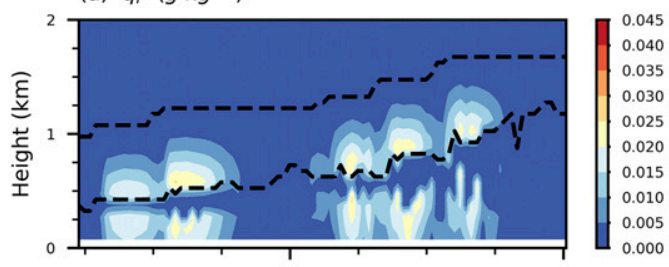

(c) in-area $q_{r}\left(g_{k g}^{-1}\right)$

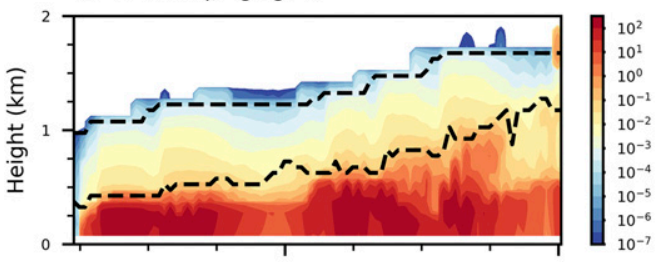

(e) $\quad V\left(q_{\text {ric }}^{*} n_{\text {ric }}^{*}\right)\left(m s^{-1}\right)$

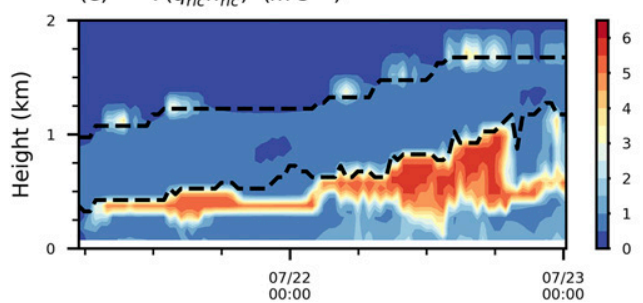

(b) rain evap $\left(\mathrm{g} \mathrm{kg}^{-1} \mathrm{day}^{-1}\right)$

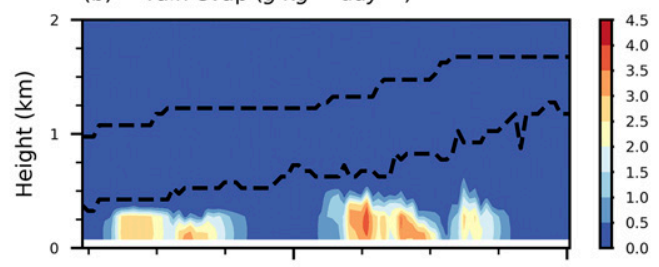

(d) $n_{r}$ self-collect $\left(1 \mathrm{~kg}^{-1} \mathrm{day}^{-1}\right)$
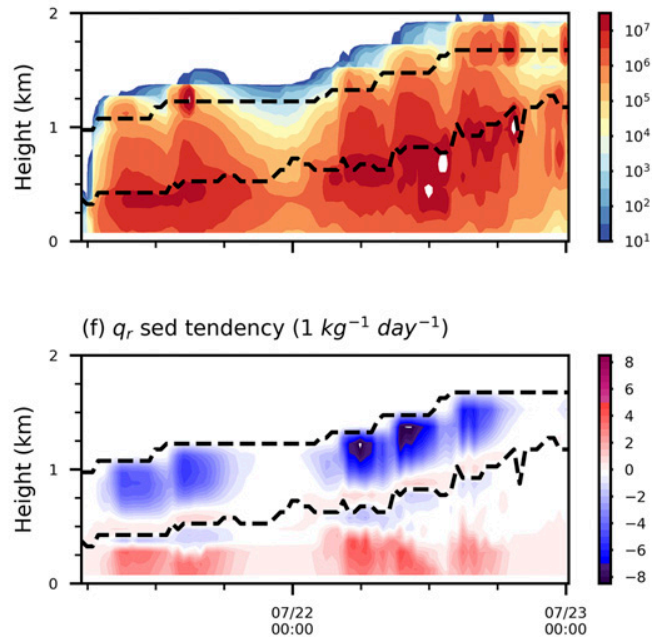

FIG. 5. Time-height evolution of (a) gridbox mean rainwater mixing ratio $q_{r}$, (b) gridbox mean precipitation evaporation rate, (c) in-area $q_{r}$, (d) in-area self-collection rate of raindrop number $n_{r}$, (e) rain fall speed for $q_{r}$ sedimentation, and (f) gridbox mean rain sedimentation tendency for the Sc phase from E3SM SCM CTL. Approximate cloud boundaries are denoted by black dashed lines that show the highest and lowest altitudes where the cloud fraction $\geq 0.1$.

the precipitation flux, and evaporation nearly sum to zero (Ghan and Easter 1992). In ARM observation and SAM LES, most rainwater evaporates near the cloud base (Figs. 6d,c), while the E3SM SCM CTL simulated rain barely evaporates until it falls far away from the cloud base (Fig. 5b).

\section{Discussion}

\section{a. Causes of unrealistic vertical structure of precipitation}

As previously mentioned, the main precipitation processes that directly change the vertical structure of rainwater below the main cloud layer are the evaporation and sedimentation of raindrops. Within each MG2 time step, sedimentation is handled separately and after all other rain processes have been calculated. Nonsedimentation processes are all computed from and applied to the same model state. Below cloud base, rain evaporation and self-collection are applied only in the fraction of each grid cell diagnosed as containing precipitation. The rain sedimentation tendency is calculated after other rain processes and it is based on the following: (i) an intermediate gridbox mean rainwater and raindrop number $\left(q_{r}^{*}\right.$ and $\left.n_{r}^{*}\right)$ that have been updated by other rain processes, and (ii) the mass-weighted fall speed $V\left(q_{\text {ric }}^{*}, n_{\text {ric }}^{*}\right)$ for rainwater sedimentation.

$$
\left(\frac{\overline{\partial q_{r}}}{\partial t}\right)_{\mathrm{sedi}}=-\frac{1}{\rho} \frac{\partial\left[\rho V\left(q_{\mathrm{ric}}^{*}, n_{\mathrm{ric}}^{*}\right) q_{r}^{*}\right]}{\partial z},
$$

where $\left(\overline{\partial q_{r}} / \partial t\right)_{\text {sedi }}$ is the gridbox mean sedimentation rate of rainwater, $\rho$ is the air density, $V\left(q_{\text {ric }}^{*}, n_{\text {ric }}^{*}\right)$ is calculated based on the size distribution of raindrops [Morrison et al. (2005), their Eq. (A4)], which is determined by the intermediate in-area rainwater $q_{\mathrm{ric}}^{*}$ and raindrop number $n_{\text {ric }}^{*}$ (Gettelman and Morrison 2015).

As a result, the parameterization of the area fraction of a grid box containing precipitation can strongly impact the precipitation processes that are calculated based on in-area rain properties, which is typical for all large-scale models (Jakob and Klein 1999, 2000). In the default version of E3SMv1, the precipitation fraction at each cloud-containing level is set to be the same as the cloud fraction in that level. Cloud-containing levels are 
ARM OBS

(a) $q_{r}\left(g \mathrm{~kg}^{-1}\right)$

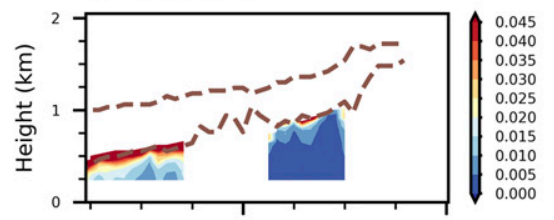

(d) Pflx gradient $\left(\mathrm{g} \mathrm{kg}^{-1} \mathrm{day}^{-1}\right)$

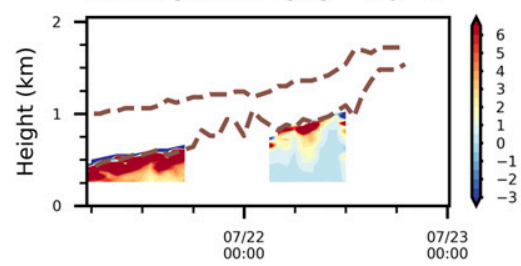

(b) $q_{r}\left(g \mathrm{~kg}^{-1}\right)$

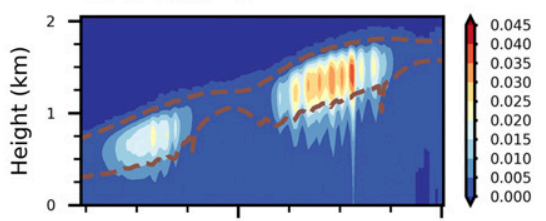

(e) Pflx gradient $\left(g \mathrm{~kg}^{-1} \mathrm{day}^{-1}\right)$

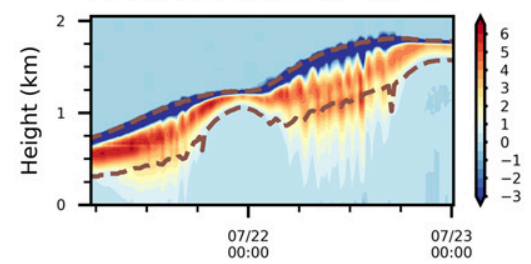

\section{SAM LES}

(c) Precip evap rate $\left(g \mathrm{~kg}^{-1} \mathrm{day}^{-1}\right)$

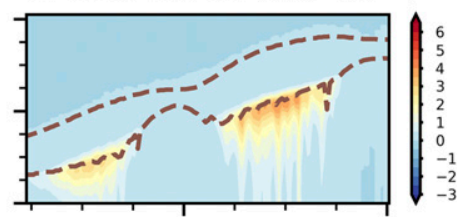

(f) $q_{r}$ sed tendency $\left(1 \mathrm{~kg}^{-1} \mathrm{day}^{-1}\right)$

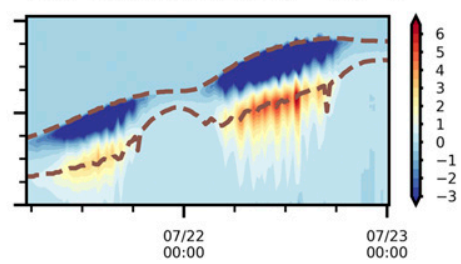

FIG. 6. Time-height evolution of (a) ARM $q_{r}$, (b) $q_{r}$ from SAM LES, (c) precipitation evaporation rate from SAM LES, (d) the vertical gradient of precipitation flux from ARM observations, (e) the vertical gradient of precipitation flux from SAM LES, and (f) the rain sedimentation rate from SAM LES for the Sc phase during Leg 15A. The ARM subcloud retrievals are available only in the layer between $200 \mathrm{~m}$ above the surface and $50 \mathrm{~m}$ below the cloud base and are shown in (a) and (d). Approximate cloud boundaries are indicated by dark brown dashed lines which show the highest and lowest altitudes where the cloud fraction $\geq 0.1$.

distinguished from clear-sky levels by having cloud water mixing ratio $>1 \times 10^{-15} \mathrm{~g} \mathrm{~kg}^{-1}$. Precipitation in all clear-sky levels below cloud are given a precipitation fraction equal to the cloud fraction of the lowest cloudcontaining level. This method is hereinafter referred to as "the in-cloud method."

In MG2, precipitation only evaporates in the precipitating portion outside of the cloudy portion of the cell, which is calculated the precipitation fraction minus the cloud fraction. Because precipitation fraction and cloud fraction are set equal to each other in cloudy layers when using the in-cloud method, rain evaporation only occurs below cloud unless the in-cloud ice and liquid water above cloud base is $<10^{-3} \mathrm{~g} \mathrm{~kg}^{-1}$. Due to the design of the in-cloud method, the rainwater at levels near the cloud base (i.e., where the cloud fraction is close to $10 \%$ ) cannot evaporate (Fig. 5b). On the other hand, because the precipitation fraction in E3SM SCM CTL is unrealistically small (Fig. $2 \mathrm{~m}$ ), the in-area rainwater $q_{\text {ric }}$ can be huge ( $>10 \mathrm{~g} \mathrm{~kg}^{-1}$ in Fig. $\left.5 \mathrm{c}\right)$. The self-collection tendency of the raindrops is proportional to $q_{\text {ric }}$ and $n_{\text {ric }}$ (Morrison and Gettelman 2008). Therefore, the large self-collection rate (Fig. 5d) significantly reduces the rain number at levels near the cloud base.

The largely reduced raindrop number $n_{\text {ric }}^{*}$ due to the self-collection of raindrops and unchanged rainwater mixing ratio result in significantly larger $V\left(q_{\mathrm{ric}}^{*}, n_{\mathrm{ric}}^{*}\right)$ at levels right above the rain evaporating zone compared with levels below and above (Fig. 5e). Closer to the surface, the rain evaporation and self-collection trigger the conservation check to prevent $n_{\text {ric }}^{*}$ and $q_{\text {ric }}^{*}$ from becoming negative, which resets $n_{\text {ric }}^{*}$ to a large value relative to $q_{\text {ric }}^{*}$ and results in small $V\left(q_{\text {ric }}^{*}, n_{\text {ric }}^{*}\right)$.

The vertical structure of $V\left(q_{\text {ric }}^{*}, n_{\text {ric }}^{*}\right)$ causes rain sedimentation to have a negative tendency near the cloud base (a narrow light blue zone near the cloud base in Fig. 5f) and a positive tendency at lower levels [Eq. (1)]. The rain sedimentation rate is applied to $q_{r}^{*}$ for the whole MG2 time step of $300 \mathrm{~s}$ without updating other rain processes. As a result, the negative tendency near cloud base causes the relative minimum in $q_{r}$ there, whereas the positive tendency at lower levels causes a relatively larger value in $q_{r}$ there. This is the explanation for the gap in the vertical profile of rainwater generated near the cloud base at the end of each model time step (Fig. 5a).

\section{b. Impacts of parameterization modifications}

In summary, we have determined that the precipitation fraction method, the unrealistic rain fall speed for rain sedimentation, and the overly long MG2 time step all contribute to the unrealistic vertical structure in $q_{r}$, precipitation evaporation and rain rate (Figs. 5 and 7). Accordingly, we conduct SCM simulations (Table 1) with shorter MG2 time steps and a different precipitation fraction method to see if they can address these problems. With regard to MG2 time step, we perform additional substeps for MG2 for each CLUBB time step of $300 \mathrm{~s}$. We test as many as 10 substeps yielding a MG2 time step as short as 30 s (Table 1). For an alternative 


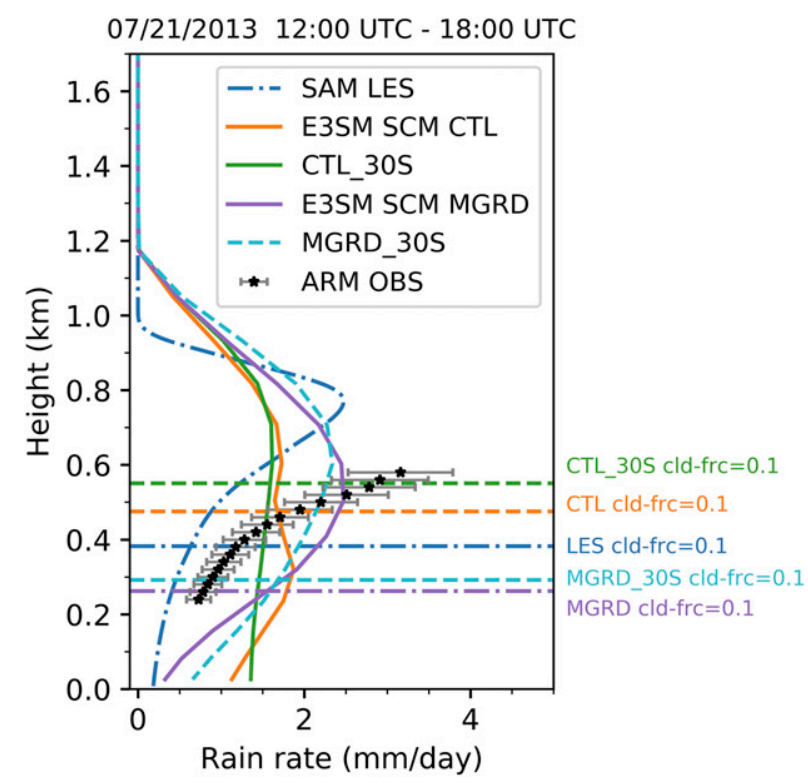

FIG. 7. Vertical profiles of the rain rate from ARM observations (black stars), SAM LES (blue dashed line), E3SM SCM CTL (orange line), E3SM SCM CTL_30S (green line), E3SM SCM MGRD (purple line), and E3SM SCM MGRD_30S (cyan dashed line) during 1200-1800 UTC 21 Jul 2013. For each case, the lowest altitude where the cloud fraction $=0.1$ is shown udinh the same color as the vertical profile. ARM rainrate observations are only available in the layer between $200 \mathrm{~m}$ above the surface and $50 \mathrm{~m}$ below the cloud base. The error bars on ARM rain rate represent the retrieval uncertainty $( \pm 20 \%)$.

precipitation fraction method, we test the "mass-gradient method," which calculates the precipitation fraction based on the cloud fraction and precipitation mass mixing ratio (appendix). With this method, the precipitation starts evaporating as soon as it falls below the level containing the maximum cloud fraction. The precipitation fraction gradually decreases as the precipitation falls away from the main cloud layer; more evaporation causes the precipitation fraction to decrease more rapidly. Other model settings for these SCM simulations are identical to E3SM SCM CTL. It should be noted that the new precipitation fraction method is used as an example of how changing the parameterization of precipitation fraction can impact the simulated precipitation and its evaporation for the regime of precipitating stratocumulus. It is not the goal of this paper to propose this parameterization for GCM implementation, which would require much more evaluation.

Figure 8 shows the vertical profiles from all $10 \mathrm{SCM}$ simulations averaged between 1200 and 1800 UTC 21 July. For SCM simulations with the default in-cloud precipitation fraction method, rain evaporation starts at higher levels as the MG2 time step decreases (Fig. 8d). This is due to a reduction in $q_{c}$ near the cloud base, which results in a raising of the level of at which the incloud $q_{c}$ falls beneath the threshold of precipitation evaporation $\left(<10^{-3} \mathrm{~g} \mathrm{~kg}^{-1}\right)$. The negative sedimentation rate near the cloud base disappears if the MG2 time step is smaller than $150 \mathrm{~s}$ (Fig. 8f) and at the same time, the unrealistic double peak structure in the vertical profile of rainwater disappears (Fig. 8a). Meanwhile, the rain fall speed increases as the MG2 time step decreases. While some of these changes are an improvement, the fractional occurrence of rain is still near zero below the cloud base for CTL_30S (Fig. 8c) even though the precipitation flux is $>2 \mathrm{~mm}^{-1 a y}{ }^{-1}$. This is the fault of the incloud method, and the fact that the rain processes are assumed to occur within a small area at each level, which generates the large rain fall speed through the whole subcloud layer (Fig. 8e). Also, the subcloud precipitation flux in CTL_30S does not clearly decrease going from cloud base to the surface, as was the case for E3SM SCM CTL (Figs. 7 and 9). The rain quickly falls down to the surface without too much evaporation (Fig. 7). Therefore, the surface rain rate from CTL_30S is clearly larger than E3SM SCM CTL and the corresponding SCM simulations with the mass-gradient method (Fig. 10). The CTL_30S PBL is dryer and more coupled (Figs. 9a and 10f) during the first 2 days and the Sc cloud layer breaks up later than E3SM SCM CTL.

For SCM simulations with the mass-gradient method, the fractional occurrence of rain becomes more realistic than simulations with the in-cloud method based on ARM observations and SAM LES (Figs. 9n,o). The rain evaporation starts at a higher level than the corresponding SCM simulations with the in-cloud method (Fig. 8j) because the criterion for precipitation evaporation with the mass-gradient method, namely that the precipitation fraction below the level of the maximum cloud fraction becomes larger than the cloud fraction, occurs as a higher level than the criterion of precipitation evaporation with in-cloud method. The magnitude of the rain evaporation is larger than the corresponding SCM simulation with the in-cloud method because the rain evaporation rate is proportional to the fractional occurrence of rain. The rain fall speed in SCM simulations with the mass-gradient method has a typical value of $1 \mathrm{~m} \mathrm{~s}^{-1}$ and is clearly smaller than that in SCM simulations with the in-cloud method. Figures 7 and 9 show that the precipitation fluxes decrease as it goes downward to the surface, albeit far less rapidly than indicated by observations or the LES. As the MG2 time step decreases, the subcloud $q_{r}$, rain evaporation rate, and rain sedimentation rate decrease, which are consistent with the SCM simulations with the in-cloud method.

The sensitivity test indicates that decreasing the MG2 time step can remove the unrealistic vertical rain 
E3SM SCM CTL

(a) $q_{r}$

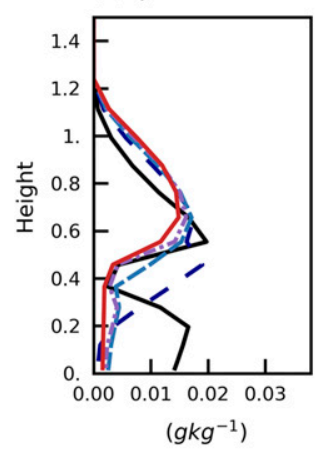

(b) $q_{c}$

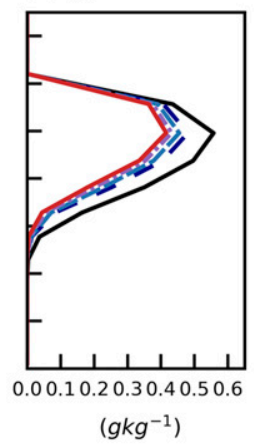

(c) fre occr of rain

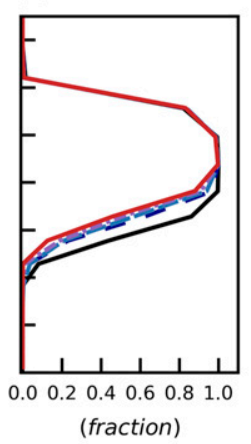

(d) qrevap

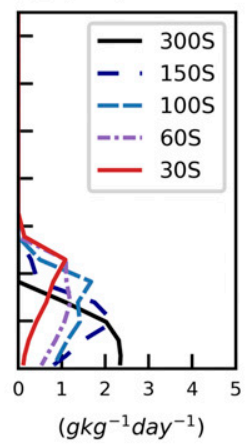

(e) rain fall speed

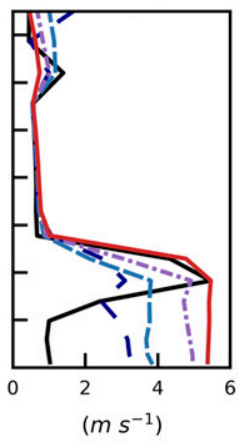

(f) $q_{r}$ sed tendency

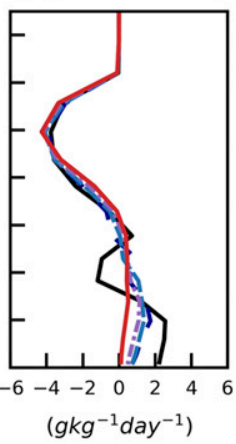

E3SM SCM MGRD

(g) $q_{r}$

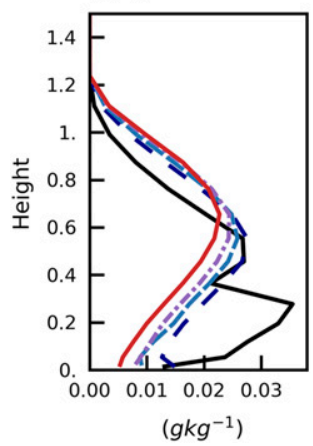

(h) $q_{c}$

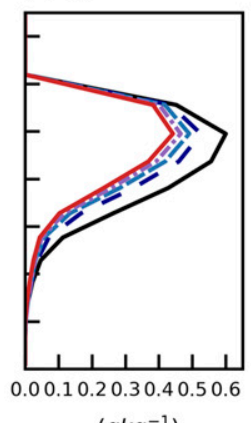

(i) fre occr of rain

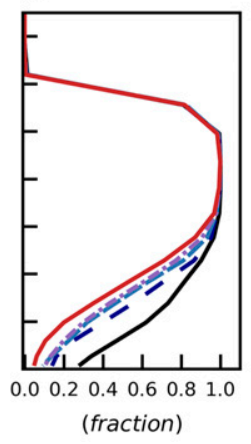

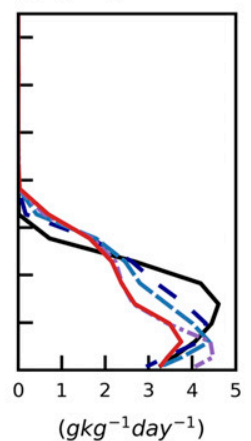

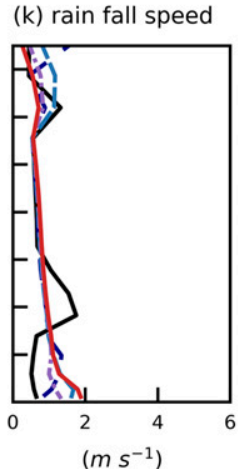

(I) $q_{r}$ sed tendency

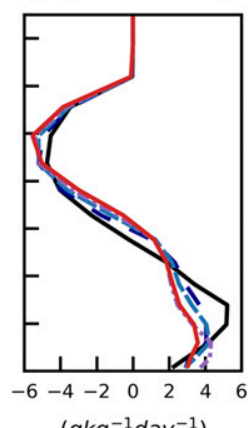

FIG. 8. (top) Vertical profiles of (a) $q_{r}$, (b) cloud water mixing ratio $\left(q_{c}\right)$, (c) fractional occurrence of rain, (d) precipitation evaporation rate, (e) rain fall speed for rainwater sedimentation, and (f) rain sedimentation rate for SCM simulations with the in-cloud method during 1200-1800 UTC 21 Jul 2013. (bottom) Vertical profiles of (g) $q_{r}$, (h) $q_{c}$, (i) fractional occurrence of rain, (j) precipitation evaporation rate, (k) rain fall speed for rainwater sedimentation, and (l) rain sedimentation rate for SCM simulations with the mass-gradient method during 1200-1800 UTC 21 Jul 2013. Black lines, navy dashed-dotted lines, blue dashed lines, purple dashed-dotted lines and red lines represent SCM simulations with a MG2 time step of $300,150,100,60$, and 30 s, respectively.

structure, remove the negative rain sedimentation rate near the cloud base, reduce the magnitude of rain evaporation and elevate the location of rain evaporation. The level with peak rain rate is elevated with the MG2 time step of $30 \mathrm{~s}$ and is closer to that in SAM LES (Fig. 7), likely because the shorter MG2 time step prevents the in-cloud rain from sedimenting too far without updating other rain processes. Another interesting aspect of the simulations is that the vertically integrated autoconversion rate $\left(\mathrm{g} \mathrm{m}^{-2} \mathrm{~s}^{-1}\right)$ systematically decreases, the vertically integrated accretion rate increases as the MG2 time step decreases (Fig. 11). Therefore, the ratio of accretion rate to autoconversion rate $\left(\mathrm{g} \mathrm{m}^{-2} \mathrm{~s}^{-1}\right)$ systematically increases as the MG2 time step decreases for both precipitation fraction methods. An increased accretion to autoconversion ratio has been found to reduce the second aerosol cloud indirect effect, reflecting the fact that the autoconversion process typically has a stronger dependency on cloud droplet number than accretion (Gettelman et al. 2015). Both autoconversion rate and accretion rate from most SCM simulations are larger than these rates from LES. The ratios of accretion to autoconversion from SCM simulations with the MG2 time step of $30 \mathrm{~s}$ are larger than LES results, which is mainly caused by a too-large accretion rate compared with LES. It is worth mentioning that SCM simulations with MG2 time steps of 150 and $100 \mathrm{~s}$ have the ratios of accretion to autoconversion closer to LES results while the major unrealistic features in vertical precipitation structure are largely mitigated (Fig. 8). On the other hand, LES results also could have biases in cloud microphysics. Observational references for these in-cloud precipitation characteristics are needed to better evaluate the model performance on these precipitation processes. 
CTL_30S

(a) $\mathrm{q}\left(g \mathrm{~kg}^{-1}\right)$

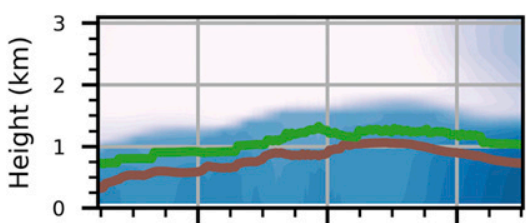

(d) $\theta(\mathrm{K})$

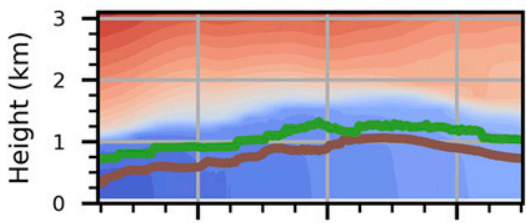

(g) Cloud Fraction

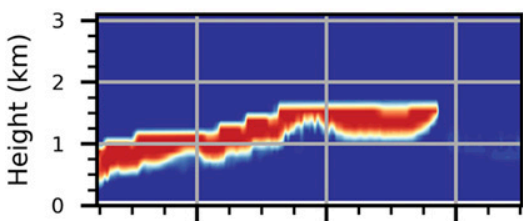

(j) Precip Flux $\left(m m d^{-1}\right)$

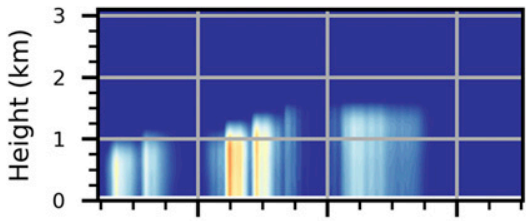

(m) Frac. Occurrence of Rain

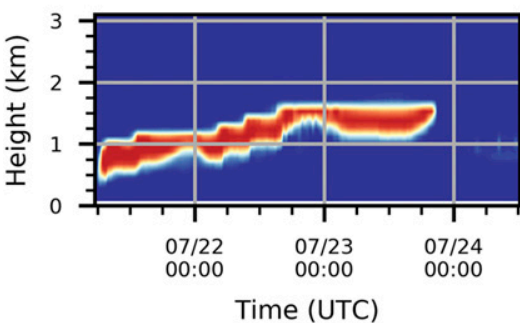

MGRD

(b) $\quad \mathrm{q}\left(g \mathrm{~kg}^{-1}\right)$

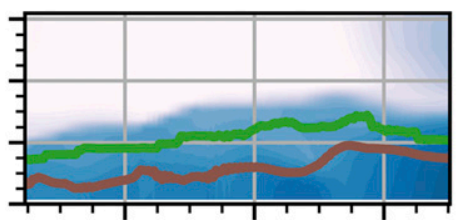

(e) $\theta(\mathrm{K})$

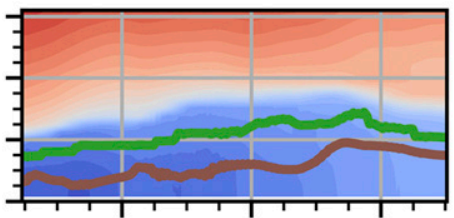

(h) Cloud Fraction

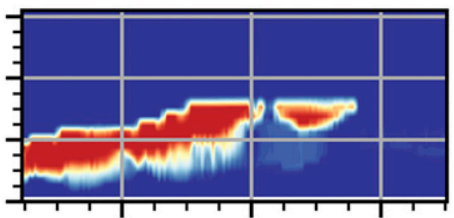

(k) Precip Flux $\left(\mathrm{mm} \mathrm{day}^{-1}\right)$

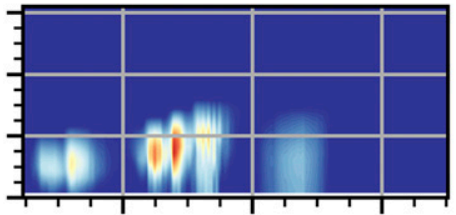

(n) Frac. Occurrence of Rain

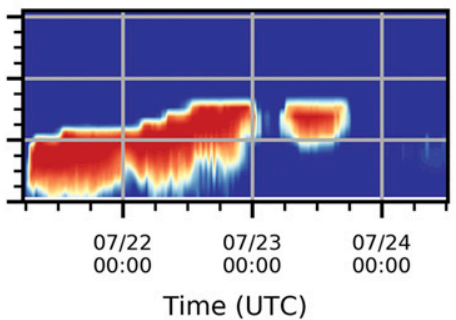

MGRD_30S

(c) $\quad \mathrm{q}\left(g \mathrm{~kg}^{-1}\right)$

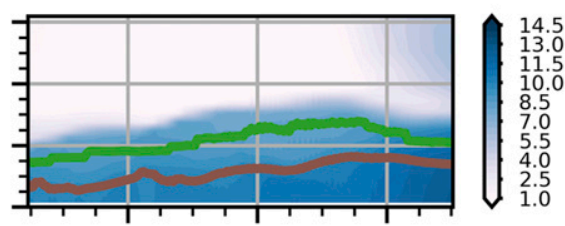

(f) $\quad \theta(\mathrm{K})$

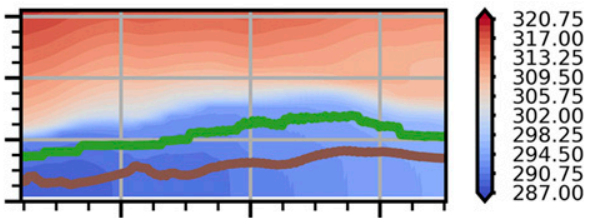

(i) Cloud Fraction

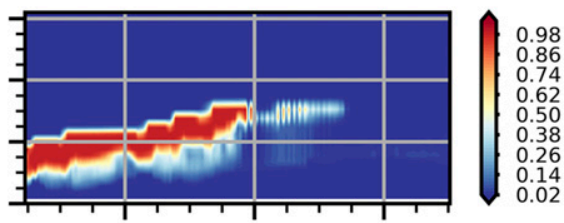

(I) Precip Flux $\left(\mathrm{mm} \mathrm{day}^{-1}\right)$

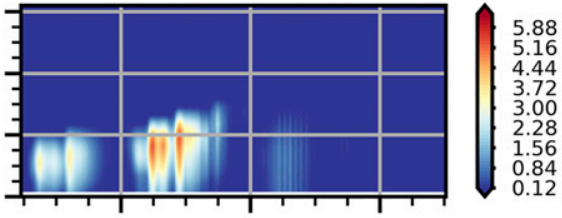

(o) Frac. Occurrence of Rain

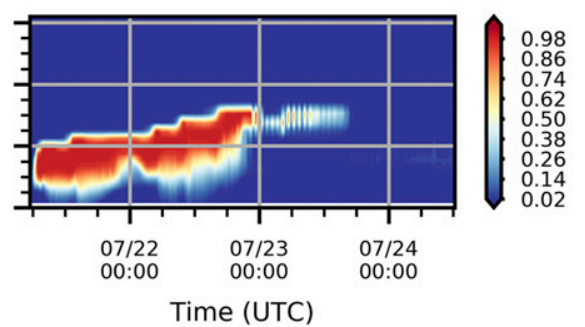

FIG. 9. As in Fig. 2, but for (left) E3SM SCM CTL_30S, (center) SCM MGRD, and (right) SCM MGRD_30S.

Changing the precipitation fraction method improves the vertical distribution of the fractional occurrence of rain and elevates the location of rain evaporation. Since the rain evaporation rate is proportional to the fractional occurrence of rain without considering the precipitation heterogeneity, the subcloud rain evaporation is clearly larger than the SCM simulations with the in-cloud method. As a result, the PBL in the SCM simulations with the massgradient method becomes slightly cooler, moister, and more decoupled, as indicated by the distance between $Z_{\mathrm{LCL}}^{150 \mathrm{~m}}$ and $Z_{\mathrm{LCL}}^{0.7 Z_{i}}$ in Fig. 9 and the surface sensible heat flux, low-level RH in Fig. 10. These changes degrade the agreement of SCM with ARM observations. The Sc cloud layer in MGRD 30S breaks up earlier than the SCM simulations with the in-cloud method. A high-frequency oscillation in cloud fraction caused by the triggering of the deep convection scheme appears after the Sc cloud layer breaks up (Fig. 9i). Previous CAM5 model evaluation found that deep convection scheme often triggers in the MBL cloud and it becomes even more active when the default shallow convection scheme, the PBL scheme and the cloud macrophysics scheme are replaced by CLUBB (Zheng et al. 2016). While switching off deep convection scheme in shallow cloud regime has been tested by E3SM model developers with different methods, the default setting of E3SMv1 still allows deep convection scheme to be 
- ARM OBS - CTL_30S MGRD --· MGRD_30S

(a) Surface Precipitation Rate

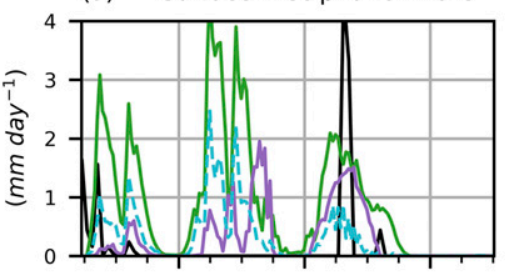

(d)

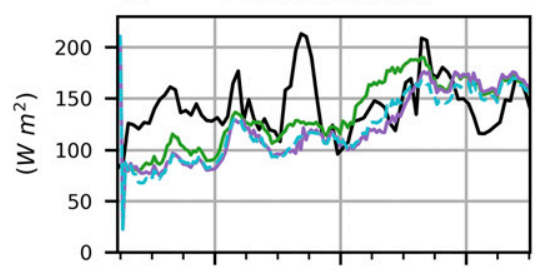

(g) Surface Downwelling LW

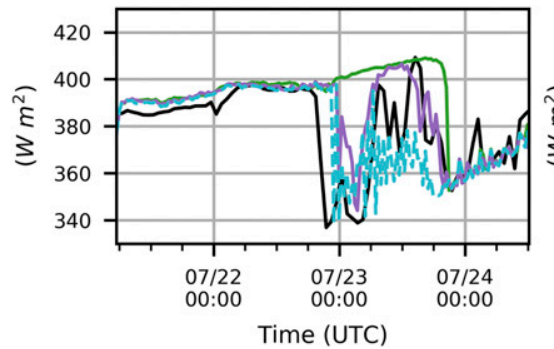

(b)

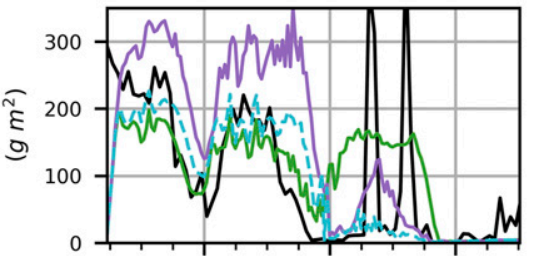

(e) Sensible Heat Flux

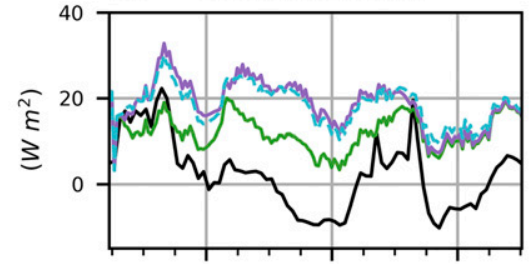

(h) Surface Downwelling SW

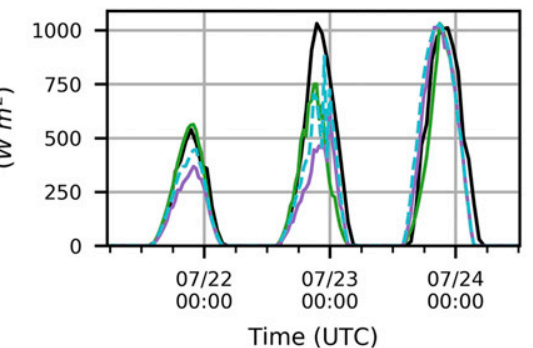

(c)

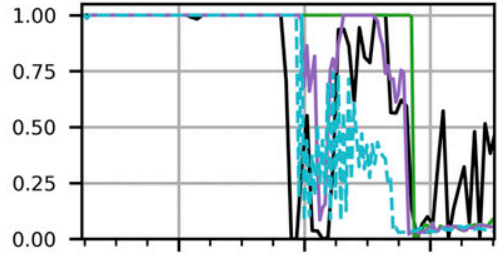

(f) Low-level RH

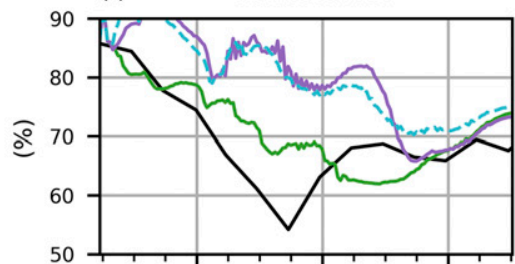

(i)

PBL Height

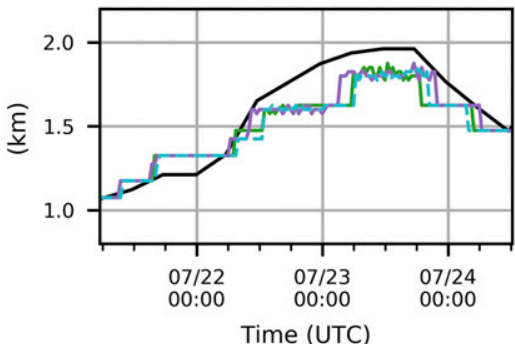

FIG. 10. Time series of (a) surface precipitation rate, (b) LWP, (c) low-level cloud cover, (d) latent heat flux, (e) sensible heat flux, (f) low-level relative humidity, (g) surface downwelling LW flux, (h) surface downwelling SW flux, and (i) PBL height. Black lines, green lines, purple lines, and cyan dashed lines represent the ARM observation, SCM CTL_30S simulation, SCM MGRD, and SCM MGRD_30S, respectively. The unit of each variable is shown on the $y$ axis.

triggered for the optimal overall model performance on the global climate.

\section{Conclusions}

In this study, we examined the ability of the newly released E3SMv1 to simulate the Sc-to-Cu transition in comparison to ARM observations and SAM LES from a case study during ARM's MAGIC field campaign. In addition to characterizing the general model performance we focused on the model's simulation of precipitation processes from overcast Sc.

The results show that under a well constrained largescale environment (i.e., a SCM setting) E3SMv1 is able to represent the realistic evolution of the PBL and cloud properties during the Sc-to-Cu transition. Improved treatment of model physics and substantially increased atmospheric vertical resolution enable E3SMv1 to capture the liquid water path and its diurnal cycle during the stratocumulus phase as well as the double-layer vertical structure of PBL thermodynamics during transition to
$\mathrm{Cu}$, suggesting E3SMv1 is capable of simulating turbulent processes within the PBL. The main biases include an underestimated growth of PBL, a delayed Sc-to- $\mathrm{Cu}$ transition and a too-cool and too-moist PBL with a toosmooth PBL inversion for Sc clouds. These biases imply that cloud-top entrainment needs to be enhanced and the PBL inversion needs to be sharper. These main findings about model performance are consistently supported by several variables from both ARM observations and SAM LES results. Examination of additional case study from MAGIC Leg 14A also supports these findings (see the supplemental materials).

Due to the model's success in simulating the stratocumulus cloud, it was possible to more closely examine the precipitation processes occurring in this phase. With help of the ARM subcloud drizzle retrievals (which used a combination of Doppler radar and backscatter lidar) and SAM LES results, we identified that the SCM has an unrealistically small subcloud precipitation fraction, an unrealistic double peak in the vertical profiles of precipitation, and the rain in SCM evaporates too close 

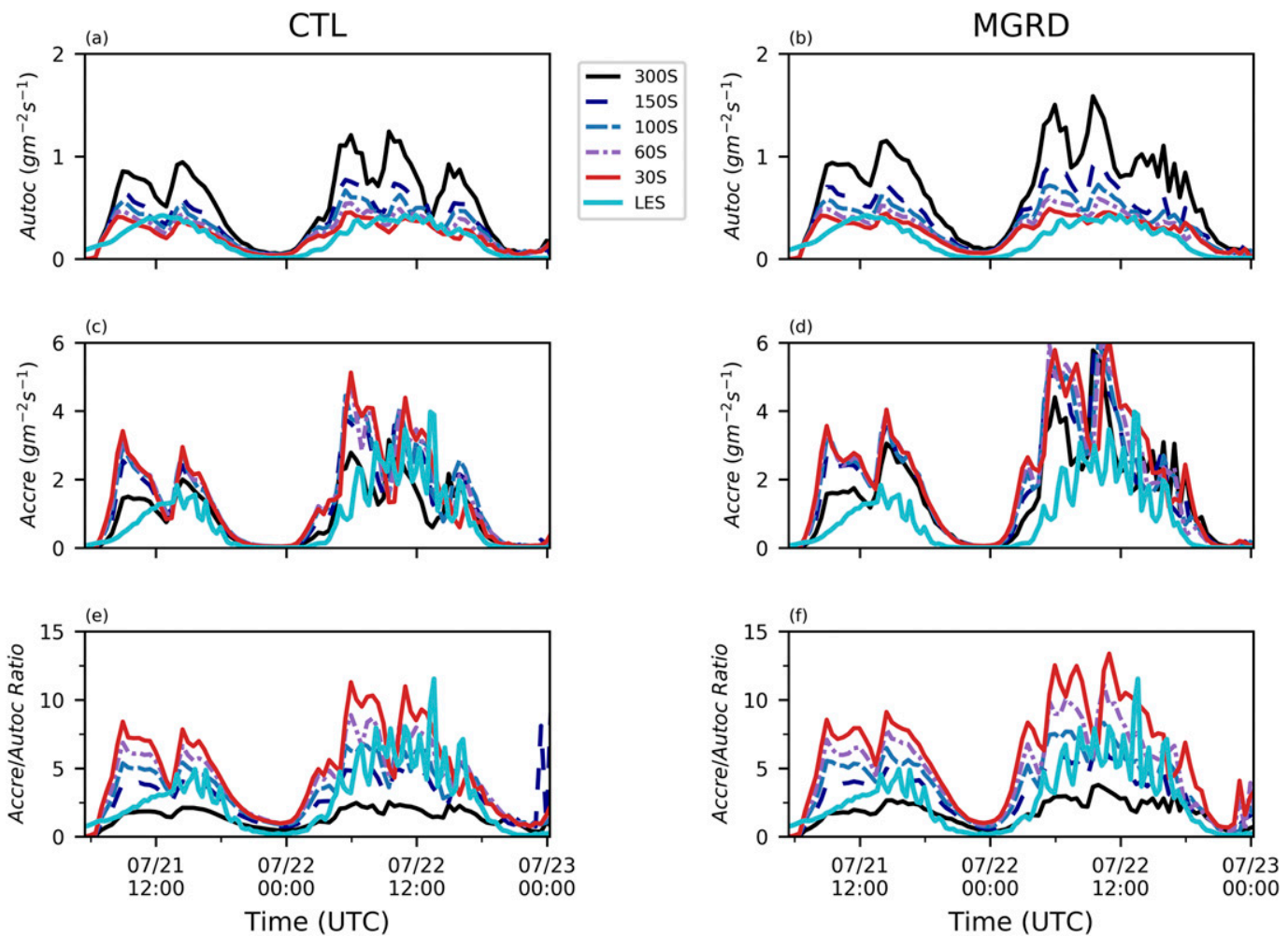

FIG. 11. Time series of the vertically integrated (a),(b) autoconversion rate, (c),(d) accretion rate, and (e),(f) the ratio of accretion to autoconversion. (left) SCM simulations with the in-cloud method and (right) SCM simulations with the massgradient method. Black lines, navy dashed-dotted lines, blue dashed lines, purple dashed-dotted lines, and red lines represent SCM simulations with a MG2 time step of 300,150,100, 60, and 30 s, respectively. Cyan lines are from SAM LES.

to the surface. These problems are caused by the calculation of rain sedimentation over an overly long microphysics time step and deficiencies in its precipitation fraction method. Using a shorter microphysics time step and a more physically based precipitation fraction method ameliorates these deficiencies. We now discuss the issues that model developers would need to consider if they were to use this information to improve the simulation of precipitation from marine stratocumulus.

At least for marine Sc, it is clear that the microphysics time step plays a critical role in determining its precipitation processes and that with its default setting of $300 \mathrm{~s}$ numerical artifacts are present. Furthermore, shortening the time step makes significant changes to physical characteristics that are known to be important for the cloud, namely, where and how much precipitation evaporates. The time step also markedly affects the ratio of accretionto-autoconversion which has implications for the simulation of aerosol-cloud interactions (Gettelman et al. 2015). Future work should examine the sensitivity of precipitation processes to time step for other cloud regimes (e.g., trade cumulus, frontal cloud, deep convection).

Future work may also be necessary to consider alternate numerical formulations to solve microphysical equations, as the increase in computational time with a shorter time step might be too great for the global model. Indeed, our global E3SMv1 simulations with $\sim 1^{\circ}$ resolution were $\sim 40 \%$ more expensive with a 30 s microphysics time step than with the default microphysics time step of $300 \mathrm{~s}$. However, a time step of 30 s may not be necessary as results suggest that time steps of 100 or 150 s already fix many of the problems in the default model with its $300 \mathrm{~s}$ time step.

On the other hand, changing the precipitation fraction method to the more physically based mass-gradient method would not induce any additional computational cost and could easily be incorporated into the model according to preliminary simulations (not shown). Relative to observations and LES, this change would improve the vertical profile of precipitation fraction. Because precipitation fraction affects drizzle sedimentation and evaporation rate, its parameterization has important effects on model climate. In our case, more realistic precipitation fraction appears to unrealistically enhance subcloud rain evaporation and degrade the relative humidity in the lower PBL. This is likely the result of tuning and development aimed at compensating for problematic precipitation fraction. One sign of this is that the PBL entrainment rate is too low, which also contributes to 
excessive humidity in the PBL. A larger entrainment rate would dry the PBL, and perhaps allow one to use a more realistic precipitation fraction method without degrading the simulation of PBL humidity. It could also be that the current formula for rain evaporation is inadequate without considering precipitation heterogeneity. Other future work should address whether the mass-gradient method for the parameterization of precipitation fraction is applicable to different precipitation regimes and to optimize values of its tunable parameters.

This study yields specific information relevant to the parameterization of large-scale model processes such as boundary layer entrainment and precipitation and demonstrates the benefits of the process-level evaluation using advanced observations and LES. Because the findings about model physical parameterizations from singlecolumn modeling are highly relevant to full GCM runs (Gettelman et al. 2019), these results should help to improve the representation of marine stratocumulus boundary layer clouds. It is also encouraging that continued advances in remote sensing have the potential to yield even more specific process-level information relevant to model improvement. For example, this study used a drizzle retrieval that is only available in the subcloud region, which hampers the ability to evaluate the model's precipitation processes (e.g., accretion-to-autoconversion ratio, precipitation efficiency) within the cloud layer. Newer ARM precipitation products that adopt advanced precipitation retrieval techniques do provide in-cloud drizzle information (Fielding et al. 2015) and these could benefit future evaluations of E3SM.

Acknowledgments. We thank the ARM data facility and the E3SM development team for providing observation data and E3SM codes. We are grateful to Peter Blossey for assistance with SAM LES integrations. We mainly used the computing resources from the National Energy Research Scientific Computing Center (NERSC). The SCM simulations and the observational analyses are available online through the NERSC Science Gateways (details provided on http://portal.nersc.gov/project/mp193/ xzheng/MAGIC). This work was funded by Atmospheric System Research (ASR) program of the U.S. Department of Energy (DOE)'s Office of Science. X. Zheng, S. A. Klein, P. Caldwell, and P. Bogenschutz were supported under the auspices of the U.S. Department of Energy by LLNL under Contract DE-AC52-07NA27344. V. P. Ghate and M. P. Cadeddu were supported by the National Science Foundation (NSF) Grant AGS1445831 awarded to the University of Chicago, and the U.S. DOE's ASR, an Office of Science, Office of Biological and Environmental Research (BER) program, under Contract DE-AC0206CH11357 awarded to the Argonne National Laboratory (LLNL-JRNL-787099).

\section{APPENDIX}

\section{Mass-Gradient Precipitation Fraction Method}

Take $f_{p, k}$ to be the precipitation fraction at grid level $k$, and $f_{c, k}$ to be the cloud fraction at level $k$. The precipitation fraction parameterizations implemented in E3SM all take the following form, which uses both the cloud fraction in a given grid cell $\left(f_{c, k}\right)$ and the precipitation fraction from the grid cell above $\left(f_{p, k-1}\right)$ to calculate the precipitation fraction at that grid cell:

$f_{p, k}=\left\{\begin{array}{l}w f_{p, k-1}+(1-w) f_{c, k} \text { if } k>1 \text { and } f_{p, k-1}>f_{c, k} \\ f_{c, k} \text { otherwise. }\end{array}\right.$

Here $w$ is some weighting function in the range $[0,1]$, which can also depend on other the state variables in levels $k$ and $k-1$. When $w$ is 1 , the precipitation fraction is simply the same as the precipitation fraction in the level above. When $w$ is 0 , or when the cloud fraction is larger than the precipitation fraction in the level above, then precipitation falling from above is ignored and all precipitation is assumed to be in cloud. In the case that all precipitation evaporates in level $k$, the precipitation fraction is typically reset to the cloud fraction. Since multiple sections of MG2 assume that the precipitation fraction is at least as large as the cloud fraction, we cannot reduce the precipitation fraction below the cloud fraction without more significant modifications to the code.

If $q_{p, k}$ is the total precipitation mass mixing ratio (rain plus snow) at level $k$, then the mass-gradient method corresponds to the following choice of $w$ :

$$
w\left(q_{p, k}, q_{p, k-1}\right)=\left\{\begin{array}{lll}
\frac{\alpha q_{p, k}+(1-\alpha) q_{p, k-1}+q_{\text {nudge }}}{q_{p, k-1}+q_{\text {nudge }}} & \text { if } \quad q_{p, k}<q_{p, k-1} \\
\frac{\beta q_{p, k-1}+(1-\beta) q_{p, k}+q_{\text {nudge }}}{q_{p, k}+q_{\text {nudge }}} & \text { if } \quad q_{p, k} \geq q_{p, k-1} .
\end{array}\right.
$$


Here $\alpha$ and $\beta$ are positive tuning parameters which are set to 2 and 1 in our simulations, and $q_{\text {nudge }}=$ $10^{-15} \mathrm{~g} \mathrm{~kg}^{-1}$ is an arbitrary, small positive constant, introduced to ensure that this method converges under refinement of the vertical grid. In particular, this form of convergence requires both continuity and that $w=1$ in the limit where all grid cells are identical. The distinction between $\alpha$ and $\beta$ is that $\alpha$ is used in cases where the rain mass decreases when altitude decreases (i.e., where evaporation is dominant) while $\beta$ covers cases where rain mass increases in lower layers (i.e., where precipitation formation outweighs evaporation). We also use a limiter to ensure that $w$ is positive, which allows $\alpha$ or $\beta$ to be set greater than 1 . In the limit where $\alpha=0$ and $\beta=0, w$ is 1 and this method becomes nearly the same as the precipitation method used in MG1 (Morrison and Gettelman 2008). Note that they are not precisely identical due to the presence of an additional limiter that MG1 uses for small amounts of precipitation, so in practice the older maximum overlap method should be used rather than setting $\alpha=\beta=0$.

Aside from satisfying these criteria, the form of $w$ is motivated by a simple heuristic. If the mass mixing ratio of precipitation is nearly the same as that in the level above, then it is likely that most precipitation is simply falling from above, and so the precipitation fraction is likely to be the same as in the level above. However, if the mass mixing ratio is very different in a given level than in the level above, then there are large sources or sinks of precipitation in that level, and precipitation is much more likely to be present inside the cloud and absent outside of it. Hence, we choose a precipitation fraction closer to the cloud fraction. (This logic holds even when the cloud fraction is zero, since in the absence of cloud, precipitation can only be evaporating, reducing the precipitation fraction. However, in practice MG2 assumes that cloud fraction is never below $10^{-4}$ in order to avoid division by zero errors, and this limit also applies to precipitation fraction.) Larger values of $\alpha$ and $\beta$ affect the strength of the weighting toward cloud fraction in the presence of strong sinks and sources of precipitation, respectively.

\section{REFERENCES}

Ahlgrimm, M., 2015: Data products from ECMWF (European Centre for Medium Range Weather Forecasts) covering the MAGIC AMF2 deployment. ECMWF, https://doi.org/ $10.5439 / 1251610$.

, and R. Forbes, 2014: Improving the representation of low clouds and drizzle in the ECMWFmodel based on ARM observations from the Azores. Mon. Wea. Rev., 142, 668-685, https://doi.org/10.1175/MWR-D-13-00153.1.
Bogenschutz, P. A., A. Gettelman, H. Morrison, V. E. Larson, D. P. Schanen, N. R. Meyer, and C. Craig, 2012: Unified parameterization of the planetary boundary layer and shallow convection with a higher-order turbulence closure in the community atmosphere model: Single-column experiments. Geosci. Model Dev., 5, 1407-1423, https://doi.org/10.5194/ gmd-5-1407-2012.

,,,,---- C. Craig, and D. P. Schanen, 2013: Higherorder turbulence closure and its impact on climate simulations in the Community Atmosphere Model. J. Climate, 26, 9655-9676, https://doi.org/10.1175/JCLI-D-13-00075.1.

Cadeddu, M. P., J. C. Liljegren, and D. D. Turner, 2013: The Atmospheric Radiation Measurement (ARM) program network of microwave radiometers: Instrumentation, data, and retrievals. Atmos. Meas. Tech., 6, 2359-2372, https://doi.org/ 10.5194/amt-6-2359-2013.

, R. Marchand, E. Orlandi, D. D. Turner, and M. Mech, 2017: Microwave passive ground-based retrievals of cloud and rain liquid water path in drizzling clouds: Challenges and possibilities. IEEE Trans. Geosci. Remote Sens., 55, 6468-6481, https://doi.org/10.1109/TGRS.2017.2728699.

Fairall, C. W., E. F. Bradley, J. E. Hare, A. A. Grachev, and J. B. Edson, 2003: Bulk parameterization of air-sea fluxes: Updates and verification for the COARE algorithm. J. Climate, 16, 571-591, https://doi.org/10.1175/1520-0442(2003)016<0571: BPOASF $>2.0 . \mathrm{CO} ; 2$.

Fielding, M. D., J. C. Chiu, R. J. Hogan, G. Feingold, E. Eloranta, E. J. O'Connor, and M. P. Cadeddu, 2015: Joint retrievals of cloud and drizzle in marine boundary layer clouds using ground-based radar, lidar and zenith radiances. Atmos. Meas. Tech., 8, 2663-2683, https://doi.org/10.5194/amt-8-2663-2015.

Flato, G., and Coauthors, 2013: Evaluation of climate models. Climate Change 2013: The Physical Science Basis, T. F. Stocker et al., Eds., Cambridge University Press, 741-866.

Gettelman, A., and H. Morrison, 2015: Advanced two-moment bulk microphysics for global models: Part I: Off-line tests and comparison with other schemes. J. Climate, 28, 1268-1287, https://doi.org/10.1175/JCLI-D-14-00102.1.

,-- S. Santos, P. Bogenschutz, and P. M. Caldwell, 2015: Advanced two-moment bulk microphysics for global models. Part II: Global model solutions and aerosol-cloud interactions. J. Climate, 28, 1288-1307, https://doi.org/10.1175/ JCLI-D-14-00103.1.

— J. E. Truesdale, J. T. Bacmeister, P. M. Caldwell, R. B. Neale, P. A. Bogenschutz, and I. R. Simpson, 2019: The Single Column Atmosphere Model version 6 (SCAM6): Not a scam but a tool for model evaluation and development. J. Adv. Model. Earth Syst., 11, 1381-1401, https://doi.org/10.1029/ 2018MS001578.

Ghan, S. J., and R. C. Easter, 1992: Computationally efficient approximations to stratiform cloud microphysics parameterization. Mon. Wea. Rev., 120,1572-1582, https://doi.org/10.1175/ 1520-0493(1992)120<1572:CEATSC >2.0.CO;2.

Ghate, V. P., and M. P. Cadeddu, 2019: Drizzle and turbulence below closed cellular marine stratocumulus clouds. J. Geophys. Res. Atmos., 124, 5724-5737, https://doi.org/ 10.1029/2018JD030141.

Golaz, J.-C., V. E. Larson, and W. R. Cotton, 2002a: A PDF-based model for boundary layer clouds. Part I: Method and model description. J. Atmos. Sci., 59, 3540-3551, https://doi.org/ 10.1175/1520-0469(2002)059<3540:APBMFB > 2.0.CO;2.

_ _ _ , and —_, 2002b: A PDF-based model for boundary layer clouds. Part II: Model results. J. Atmos. Sci., 59, 
3552-3571, https://doi.org/10.1175/1520-0469(2002)059<3552: APBMFB $>2.0 . \mathrm{CO} ; 2$.

- and Coauthors, 2019: The DOE E3SM coupled model version 1: Overview and evaluation at standard resolution. J. Adv. Model. Earth Syst., 11, 2089-2129, https://doi.org/10.1029/2018MS001603.

Guo, Z., M. Wang, V. E. Larson, and T. Zhou, 2019: A cloud top radiative cooling model coupled with CLUBB in the Community Atmosphere Model: Description and simulation of low clouds. J. Adv. Model. Earth Syst., 11, 979-997, https://doi.org/10.1029/2018MS001505.

Hartmann, D. L., M. E. Ockert-Bell, and M. L. Michelsen, 1992: The effect of cloud type on earth's energy balance-Global analysis. J. Climate, 5, 1281-1304, https://doi.org/10.1175/15200442(1992)005<1281:TEOCTO >2.0.CO;2.

Jakob, C., and S. A. Klein, 1999: The role of vertically varying cloud fraction in the parametrization of microphysical processes in the ECMWF model. Quart. J. Roy. Meteor. Soc., 125, 941-965, https://doi.org/10.1002/qj.49712555510.

—_, and — 2000: A parameterization of the effects of cloud and precipitation overlap for use in general-circulation models. Quart. J. Roy. Meteor. Soc., 126, 2525-2544, https://doi.org/10.1002/qj.49712656809.

Jones, C. R., C. S. Bretherton, and D. Leon, 2011: Coupled vs. decoupled boundary layers in VOCALS-REx. Atmos. Chem. Phys., 11, 7143-7153, https://doi.org/10.5194/acp-11-7143-2011.

Karlsson, J., G. Svensson, S. Cardoso, J. Teixeira, and S. Paradise, 2010: Subtropical cloud-regime transitions: Boundary layer depth and cloud-top height evolution in models and observations. J. Appl. Meteor. Climatol., 49, 1845-1858, https://doi.org/ 10.1175/2010JAMC2338.1.

Khairoutdinov, M. F., and D. A. Randall, 2003: Cloud resolving modeling of the ARM summer 1997 IOP: Model formulation, results, uncertainties, and sensitivities. J. Atmos. Sci., 60, 607-625, https://doi.org/10.1175/1520-0469(2003)060<0607: CRMOTA $>2.0 . \mathrm{CO} ; 2$.

Kubar, T. L., G. L. Stephens, M. Lebsock, V. E. Larson, and P. A. Bogenschutz, 2015: Regional assessments of low clouds against largescale stability in CAM5 and CAM-CLUBB using MODIS and ERA-Interim reanalysis data. J. Climate, 28, 1685-1706, https://doi.org/10.1175/JCLI-D-14-00184.1.

Larson, V. E., and J.-C. Golaz, 2005: Using probability density functions to derive consistent closure relationships among higher-order moments. Mon. Wea. Rev., 133, 1023-1042, https://doi.org/10.1175/MWR2902.1.

Lewis, E. R., 2016: Marine ARM GPCI investigation of clouds (MAGIC) field campaign report. Tech. Rep. DOE/SC-ARM16-057, DOE ARM Climate Research Facility, https://doi.org/ $10.2172 / 1343577$.

—_ and J. Teixeira, 2015: Dispelling clouds of uncertainty. Eos, Trans. Amer. Geophys. Union, 96, https://doi.org/10.1029/ 2015EO031303.

Lin, J., T. Qian, and T. Shinoda, 2014: Stratocumulus clouds in southeastern Pacific simulated by eight CMIP5-CFMIP global climate models. J. Climate, 27, 3000-3022, https://doi.org/ 10.1175/JCLI-D-13-00376.1.

McGibbon, J., and C. S. Bretherton, 2017: Skill of ship-following large-eddy simulations in reproducing MAGIC observations across the northeast Pacific stratocumulus to cumulus transition region. J. Adv. Model. Earth Syst., 9, 810-831, https:// doi.org/10.1002/2017MS000924.

Morrison, H., and A. Gettelman, 2008: A new two-moment bulk stratiform cloud microphysics scheme in the Community Atmosphere Model, version 3 (CAM3). Part I: Description and numerical tests. J. Climate, 21, 3642-3659, https://doi.org/ 10.1175/2008JCLI2105.1.

— J. A. Curry, and V. I. Khvorostyanov, 2005: A new doublemoment microphysics parameterization for application in cloud and climate models. Part I: Description. J. Atmos. Sci., 62, 1665-1677, https://doi.org/10.1175/JAS3446.1.

Neale, R. B., J. H. Richter, and M. Jochum, 2008: The impact of convection on ENSO: From a delayed oscillator to a series of events. J. Climate, 21, 5904-5924, https://doi.org/10.1175/ 2008JCLI2244.1.

Neggers, R. A. J., and Coauthors, 2017: Single-column model simulations of subtropical marine boundary-layer cloud transitions under weakening inversions. J. Adv. Model. Earth Syst., 9, 2385-2412, https://doi.org/10.1002/2017MS001064.

O'Connor, E. J., R. J. Hogan, and A. J. Illingworth, 2005: Retrieving stratocumulus drizzle parameters using Doppler radar and lidar. J. Appl. Meteor., 44, 14-27, https://doi.org/ 10.1175/JAM-2181.1.

Quaas, J., and Coauthors, 2009: Aerosol indirect effects-General circulation model intercomparison and evaluation with satellite data. Atmos. Chem. Phys., 9, 8697-8717, https://doi.org/ 10.5194/acp-9-8697-2009.

Rasch, P. J., and Coauthors, 2019: An overview of the atmospheric component of the energy exascale earth system model. J. Adv. Model. Earth Syst., 11, 2377-2411, https://doi.org/10.1029/ 2019MS001629.

Rémillard, J., P. Kollias, E. Luke, and R. Wood, 2012: Marine boundary layer cloud observations in the Azores. J. Climate, 25, 7381-7398, https://doi.org/10.1175/JCLI-D-11-00610.1.

Richter, J., and P. Rasch, 2008: Effects of convective momentum transport on the atmospheric circulation in the Community Atmosphere Model, version 3. J. Climate, 21, 1487-1499, https://doi.org/10.1175/2007JCLI1789.1.

Song, H., Z. Zhang, P.-L. Ma, S. J. Ghan, and M. Wang, 2018: An evaluation of marine boundary layer cloud property simulations in the Community Atmosphere Model using satellite observations: Conventional subgrid parameterization versus CLUBB. J. Climate, 31, 2299-2320, https://doi.org/10.1175/ JCLI-D-17-0277.1.

Teixeira, J., and Coauthors, 2011: Tropical and subtropical cloud transitions in weather and climate prediction models: The GCSS/WGNE Pacific Cross-Section Intercomparison (GPCI). J. Climate, 24, 5223-5256, https://doi.org/10.1175/ 2011JCLI3672.1.

Wood, R., 2012: Stratocumulus clouds. Mon. Wea. Rev., 140, 2373-2423, https://doi.org/10.1175/MWR-D-11-00121.1.

— , and Coauthors, 2016: Planning the next decade of coordinated research to better understand and simulate marine low clouds. Bull. Amer. Meteor. Soc., 97, 1699-1702, https:// doi.org/10.1175/BAMS-D-16-0160.1.

Wyant, M. C., and Coauthors, 2010: The PreVOCA experiment: Modeling the lower troposphere in the southeast Pacific. Atmos. Chem. Phys., 10, 4757-4774, https://doi.org/10.5194/ acp-10-4757-2010.

Xiao, H., and Coauthors, 2014: Diagnosis of the marine low cloud simulation in the NCAR Community Earth System Model (CESM) and the NCEP Global Forecast System (GFS)Modular Ocean Model v4 (MOM4) coupled model. Climate Dyn., 43, 737-752, https://doi.org/10.1007/s00382-014-2067-y.

Xie, S., and Coauthors, 2018: Understanding cloud and convective characteristics in version 1 of the E3SM atmosphere model. J. Adv. Model. Earth Syst., 10, 2618-2644, https://doi.org/ 10.1029/2018MS001350. 
Zhang, G. J., and N. A. McFarlane, 1995: Role of convective scale momentum transport in climate simulation. J. Geophys. Res. 100, 1417-1426, https://doi.org/10.1029/94JD02519.

Zheng, X., S. A. Klein, H.-Y. Ma, P. Bogenschutz, A. Gettelman, and V. E. Larson, 2016: Assessment of marine boundary layer cloud simulations in the CAM with CLUBB and updated microphysics scheme based on ARM observations from the Azores. J. Geophys. Res. Atmos., 121, 8472-8492, https://doi.org/ 10.1002/2016JD025274.
P. Caldwell, V. E. Larson, A. Gettelman, and P. Bogenschutz, 2017: A cloudy planetary boundary layer oscillation arising from the coupling of turbulence with precipitation in climate simulations. J. Adv. Model. Earth Syst., 9, 1973-1993, https://doi.org/10.1002/2017MS000993.

Zhou, X., P. Kollias, and E. R. Lewis, 2015: Clouds, precipitation and marine boundary layer structure during the MAGIC field campaign. J. Climate, 28, 2420-2442, https://doi.org/10.1175/ JCLI-D-14-00320.1. 